Article

\title{
The Large Dendritic Morphologies in the Antoniadi Crater (Mars) and Their Potential Astrobiological Significance
}

\author{
Fabio Vittorio De Blasio (D)
}

check for updates

Citation: De Blasio, F.V. The Large Dendritic Morphologies in the Antoniadi Crater (Mars) and Their Potential Astrobiological Significance. Geosciences 2022, 12, 53. https:// doi.org/10.3390/geosciences12020053

Academic Editors: Alberto G. Fairén and Jesus Martinez-Frias

Received: 21 December 2021

Accepted: 20 January 2022

Published: 24 January 2022

Publisher's Note: MDPI stays neutral with regard to jurisdictional claims in published maps and institutional affiliations.

Copyright: (c) 2022 by the author. Licensee MDPI, Basel, Switzerland. This article is an open access article distributed under the terms and conditions of the Creative Commons Attribution (CC BY) license (https:// creativecommons.org/licenses/by/ $4.0 /)$.
Department of Earth and Environmental Sciences, Università degli Studi di Milano-Bicocca, Piazza Della Scienza 4, 20126 Milan, Italy; fabio.deblasio@unimib.it

\begin{abstract}
Mars has held large amounts of running and standing water throughout its history, as evidenced by numerous morphologies attributed to rivers, outflow channels, lakes, and possibly an ocean. This work examines the crater Antoniadi located in the Syrtis Major quadrangle. Some parts of the central area of the crater exhibit giant polygonal mud cracks, typical of endured lake bottom, on top of which a dark, tens of kilometers-long network of dendritic (i.e., arborescent) morphologies emerges, at first resembling the remnant of river networks. The network, which is composed of tabular sub-units, is in relief overlying hardened mud, a puzzling feature that, in principle, could be explained as landscape inversion resulting from stronger erosion of the lake bottom compared to the endured crust of the riverine sediments. However, the polygonal mud cracks have pristine boundaries, which indicate limited erosion. Furthermore, the orientation of part of the network is the opposite of what the flow of water would entail. Further analyses indicate the similarity of the dendrites with controlled diffusion processes rather than with the river network, and the presence of morphologies incompatible with river, alluvial, or underground sapping processes, such as overlapping of branches belonging to different dendrites or growth along fault lines. An alternative explanation worth exploring due to its potential astrobiological importance is that the network is the product of ancient reef-building microbialites on the shallow Antoniadi lake, which enjoyed the fortunate presence of a heat source supplied by the Syrtis Major volcano. The comparison with the terrestrial examples and the dating of the bottom of the crater (formed at $3.8 \mathrm{Ga}$ and subjected to a resurfacing event at $3.6 \mathrm{Ga}$ attributed to the lacustrine drape) contribute to reinforcing (but cannot definitely prove) the scenario of microbialitic origin for dendrites. Thus, the present analysis based on the images available from the orbiters cannot be considered proof of the presence of microbialites in ancient Mars. It is concluded that the Antoniadi crater could be an interesting target for the research of past Martian life in future landing missions.
\end{abstract}

Keywords: Antoniadi; Martian life; stromatolites; dendritic growth

\section{Introduction}

The quest for possible ancient forms of life in the Universe and, in particular, for Martian life is largely a search for areas of former water abundance, e.g., [1-4]. Morphological indications for water include outflow channels between the southern highlands and the north plains, and valley networks carved on ancient and cratered areas of the planet [5-10]. In addition, numerous clues indicate that the northern plains were once an oceanic floor [6,11,12]. Further evidence of abundant water in the past of Mars is provided by mineralogical spectra in both reflectance and emissivity that indicate the presence of phyllosilicates [13], by the sedimentological analysis of equatorial layered deposits presumably deposited in aqueous environment [14], by the presence of deltas [15-17], and by morphological features (e.g., [18-21]). Ancient lakes are arguably the most promising water reservoirs for past Martian life research [6,22]. Several observations indicate that the lakes may have ponded morphological lows [23] or resided in structural basins such as Valles Marineris [24,25], the giant impact basins of Hellas and Argyre Planitiae [26], 
and impact craters $[26,27]$. The presence of crater lakes on Mars is particularly interesting because the flat bottom of the impact craters and the lack of outlets may have favored the stillness of the water and a persistent water level. The proposed craters that previously hosted lakes, such as Eberswalde, Gusev, Gale, Endeavour, and Jezero, have been, or will be, the subject of robotic investigations [28]. However, the surveyed areas are characterized either by complex distribution patterns of the water flow, or by Gilbert-type deltas which indicate, in both cases, a strong energy of the water flow in the crater (e.g., [15,29]). The scarcity of biological signatures even in ancient river environments on Earth [30] indicates that the stressful drag forces exerted by water flowing at the bottom of a river may be an obstacle to the growth of primitive microbial life in river environments compared to calm lake waters. Therefore, the search for ancient microbial life on Mars probably has better chances in ancient lake sedimentary environments.

This work examines Antoniadi, a large and shallow crater in the Isidis-Syrtis Major area. A prime reason to study this particular crater is that, similarly to other ancient Martian craters, an inspection of its floor shows that the crater probably held a lake. The subjects of this work, in particular, are the peculiar dendritic morphologies that can be identified in some locations within the crater, and their possible astrobiological significance. Except for a study of the mineralogy of the area southeast of Antoniadi, where the presence of diagenetic quartz was established [31,32], there are no works entirely dedicated to this crater and its dendritic morphologies.

\section{The Antoniadi Crater}

\subsection{General Description}

Antoniadi is a $400 \mathrm{~km}$ wide impact crater located in the Syrtis Major quadrangle at the coordinates $21^{\circ} \mathrm{N}$ and $230^{\circ} \mathrm{W}$ (Figure 1). Apart from small local roughness visible in the CTX images (Figure 1A), the crater bottom is essentially flat, showing variations of only some tens of meters along a baseline of $100 \mathrm{~km}$. Moreover, it is, on average, only $1200 \mathrm{~m}$ below the crater rim. Because a crater of this diameter should be about three times deeper [33], this indicates the presence of internal deposits (Figure 1B). The crater lies on the northwestern flank of the Syrtis Major volcano and postdates its largest lava fields (Figure 1B).

Figure 1E, very schematically, shows the geomorphology inside the Antoniadi crater. As an ancient crater (see below), Antoniadi was subjected to intense meteoroid bombardment that shaped at least 13 craters wider than $10 \mathrm{~km}$, and numerous smaller ones. Thus, nearly half of the crater area is covered with ejecta material that radiates from some of the larger impact centers. Possible lava flows from Syrtis Major mixed with indeterminate units emerge in the southern part, while two large areas, one to the north and one to the south, appear in the CTX, THEMIS, and HiRISE images as altered by diverse geological and geomorphological factors such as faults and periglacial processes. They have been generically referred to as "uneven terrain" in Figure 1E. Notably, the uneven terrain to the south includes a large crater with internal material broken into chaos-like fractures, which would indicate water or ice filling [34]. The ground inside Antoniadi also appears varied with regard to the infrared emission, which indicates the coexistence of blocky terrain, probably containing regolith (maximum thermal inertia in the TI area in Figure 1E) and dusty soils. The smoother area within the crater appears toward the center ("smooth terrain" in Figure 1E), possibly indicating a different sedimentation process. It is within this smooth terrain that the dendrites are visible, as seen in the HiRISE images. Areas with dendrites appear in three locations, all located in the southern part of the Antoniadi crater: a western unit, $\mathrm{W}$, a central unit, C, and an eastern unit, E. Note that the high-resolution images needed to locate the dendritic areas do not cover the entire crater area, and more interesting features may be found with future high-resolution images. 

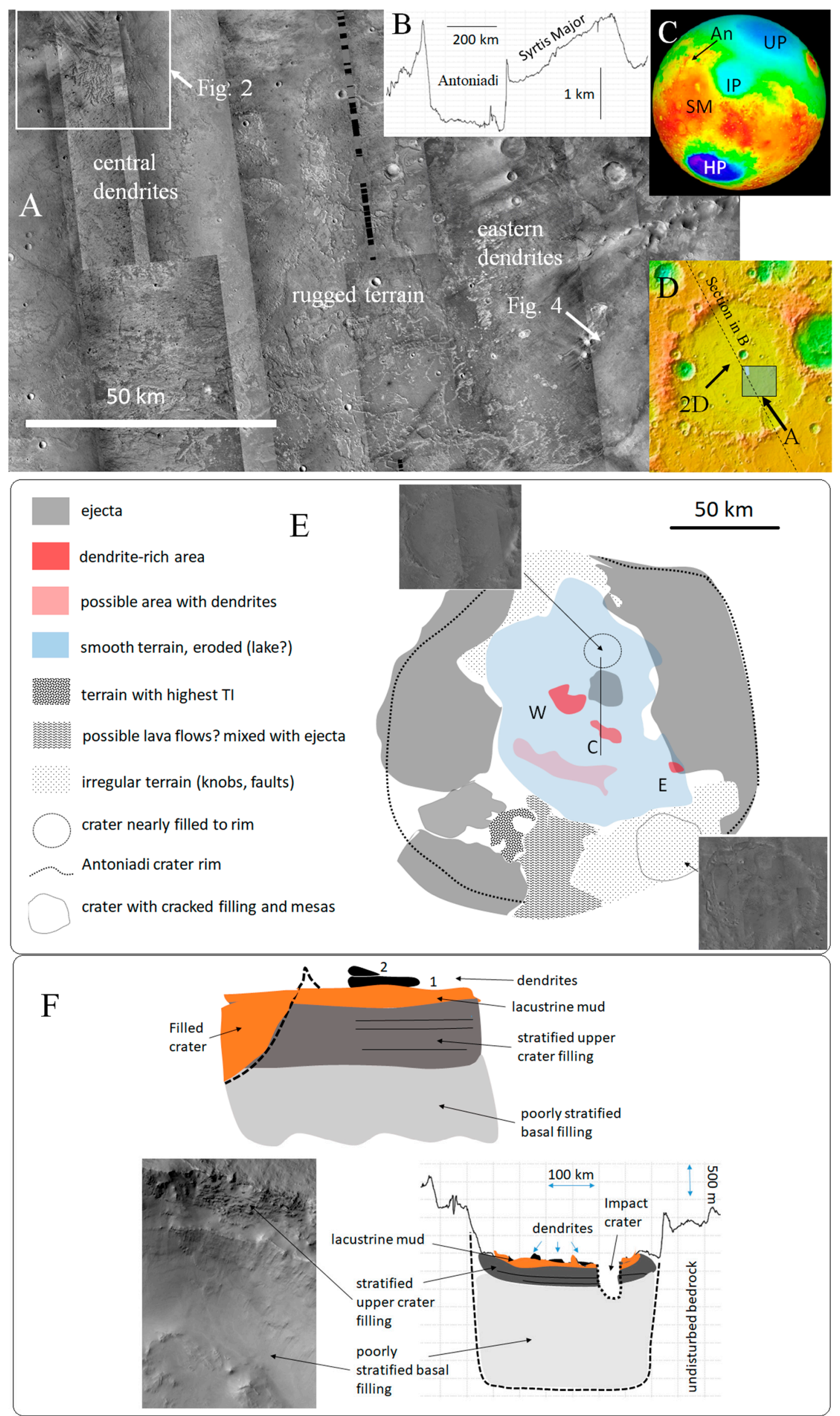

Figure 1. The Antoniadi crater. (A) The roughness of the crater floor is evident in this CTX mosaic. 
Dendrites are particularly well developed in the three spots in western, central, and eastern areas of the southern half of the crater. The area inside the white rectangle is expanded in Figure 2. The W dendrites shown in Figure 3 are outside the map, while the arrow shows the location of the detailed area shown in Figure 4. (B) Cross section of the MOLA altimeter data from NW to SE through the Antoniadi crater to the Syrtis Major volcano. Part of the section is represented in (D). (C) Location of Antoniadi (An) displayed on shaded MOLA. "SM" indicates the Syrtis Major volcanic building, "UP", "IP", and "HP" are, respectively, the impact basins of Utopia, Isidis, and Hellas Planitiae. (D) The area of the Antoniadi crater, colored hillshade MOLA, which marks the area in (A) with a shaded rectangle. The dotted line is the northern part of the MOLA altimeter section shown in (B). (E) Highly schematic map of the main geomorphological features of Antoniadi. (F) Ideal stratigraphic scheme of the filling material inside central Antoniadi as deduced from examination of the sections of impact craters and faults. The section approximately corresponds to the vertical line drawn in $\mathrm{E}$ (crater ejecta not considered for simplicity).
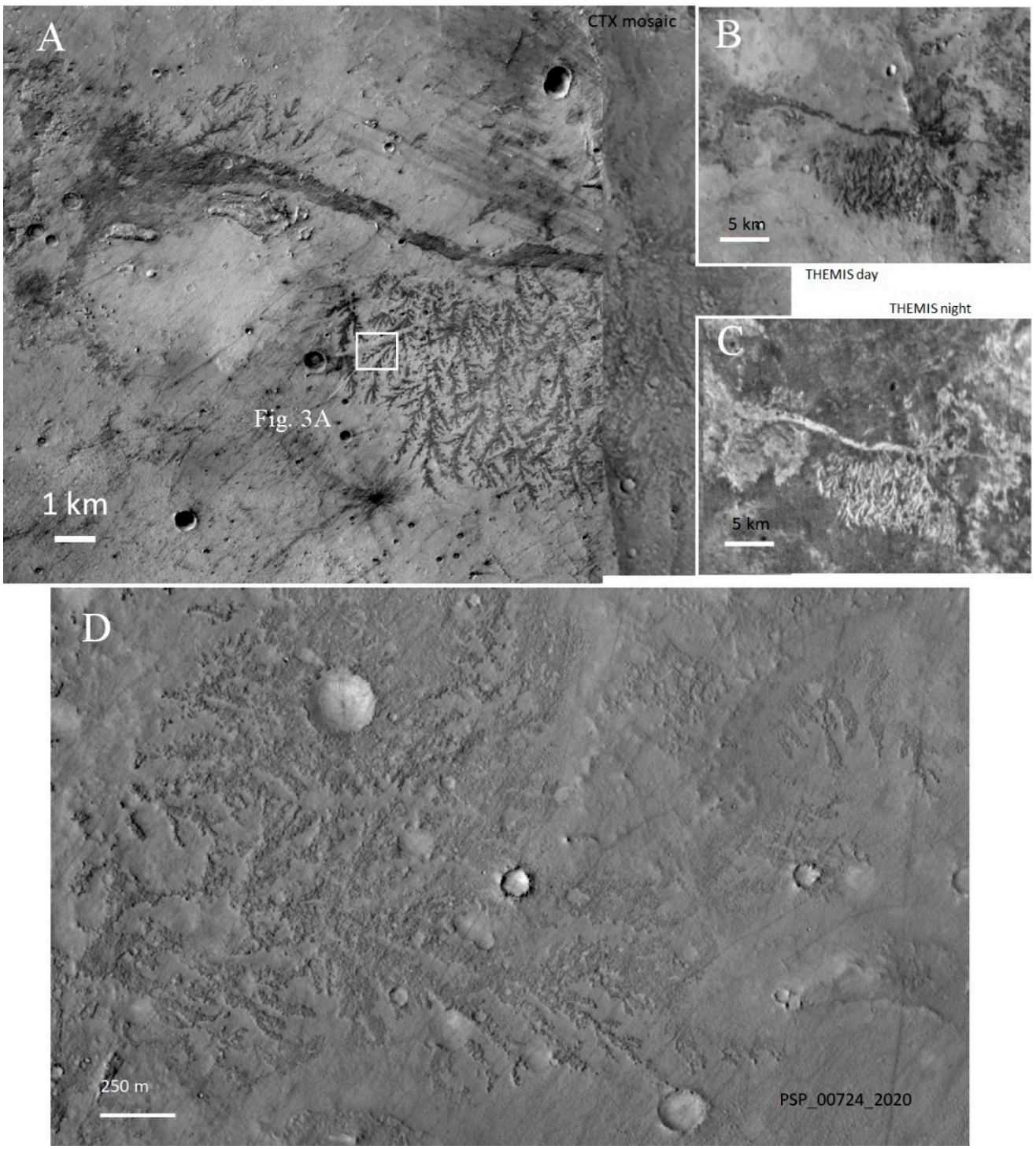

Figure 2. (A) Expanded area inside the white rectangle in Figure 1A, with a more detailed image of the central dark dendritic morphologies. The white rectangle is further enlarged in Figure 3A. (B) THEMIS day infrared image of the same area. (C) THEMIS night infrared image of the same area. (D) Image of the $\mathrm{W}$ dendrites. Location area in Figure 1D. 

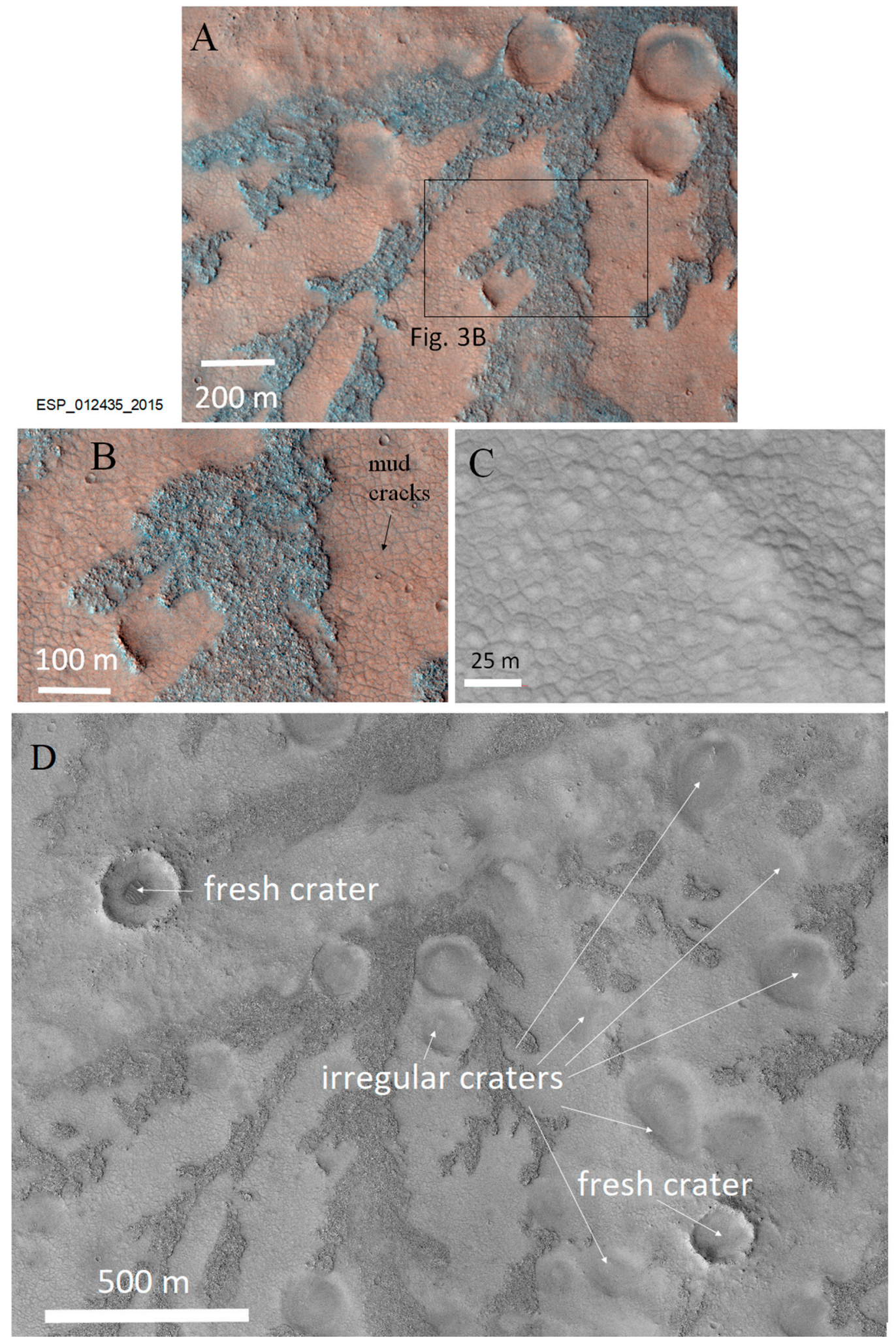

Figure 3. Appearance of the dendrites in the central unit (area shown in Figure 2A). HiRISE image ESP_012435_2015. (B) Enlarged rectangle in (A). (C) Enlarged image to show the polygonal ground (area outside Figure 3A). (D) Image of fresh and irregular impact craters on the putative lacustrine floor. The three craters in the center are the same appearing in the top-right of (A). All HiRISE images courtesy of NASA/JPL/University of Arizona. 


\subsection{The Dendrites}

Within the southern half of the crater, areas with peculiar dendritic structures appear [35,36], as shown in Figures 1A and 2A. Dendrites can be observed in three spots: one located to the west, one near the center of the crater, and one to the east (Figure 1E). Of the three units, the central dendrites are well visible on a CTX image at the scale of tens of kilometers, as shown in Figure 1A, while the other two units require more detailed images. The central and eastern units are shown in Figure 1A. The western dendrites are somehow more poorly preserved and will be considered in less detail (Figure 2D). HiRISE imaging shows that, while the central dendrites are composed of blocky material (Figure 3), the eastern units are subdivided into tabular polygonal sub-elements about $15-18 \mathrm{~m}$ in diameter (Figure 4). A notable feature visible in the high-resolution images is the subdivision of part of the terrain of the crater bottom into polygons of about $10-20 \mathrm{~m}$ in diameter (Figure 3B,C). Note also that the dendrites lie stratigraphically on the terrain on which such polygons are imposed (Figure 1F). Many different processes (including periglacial activity, extremely common on Mars even at these low latitudes) may create polygonal patterns [37]. However, considering the commonness of craters in the Martian highlands filled with lacustrine sediments [26], and the similarity between the polygons in Antoniadi and giant mud cracks in lacustrine sediments of terrestrial deserts [38], it is more likely that the polygons are giant mud cracks created during the desiccation of the smectite-bearing lake bottom inside Antoniadi $[35,39]$.

A further indication of the lacustrine nature of the polygon-rich area is the irregular shape of some of the impact craters on the surface. Figure 3D shows some of these irregular craters coexisting with craters of typical circular shape. Note the wavy and slightly scalloped outline of the irregular craters and their smoother appearance in contrast to the normal craters which are sharper, more rounded, and often exhibit a tiny halo of ejected material. Most irregular craters have a size on the order of $100 \mathrm{~m}$, although smaller craters of this type can also be seen in the high-resolution images (see also the following figures). Here, they are interpreted as the result of impacts on soft ground, and in the presence of a layer of water. The water would have affected the dynamics of the impact, causing a spray of lacustrine sediments on the lake floor and thus altering the final shape of the crater. For example, note that irregular craters with a diameter of $100 \mathrm{~m}$, such as those in Figure 3, would be produced by a meteoroid ranging in size from some meters to one decameter [40] if impact occurred in the absence of a layer of water. Therefore, a few meters, up to tens of meters, of water (possibly not pure but mixed with mud) would be enough to alter the size and shape of a crater produced by an impactor of this size. The normal craters were probably formed after the complete disappearance of water and the surface was hardened (Figure 3D). In addition, some craters incised on the dendrites appear irregular, indicating that the surface of the dendrites may have been soft and underwater during the impacts.

The stratigraphy of the two upper kilometers within Antoniadi can be partially reconstructed based on HiRISE images in areas excavated by the largest impacts and by other exposures in correspondence of fractures (Figure 1F). Below the first few hundred meters or so of stratified rocks, the deeper crater filling appears less stratified. The alleged lacustrine mud in the central area of the crater probably rests on top of the stratified deposits. The infrared THEMIS images show a contrast between low diurnal emission (Figure 2B) and strong nocturnal signal (Figure 2C) for the dendrites, indicating that the surface retains much heat during the night. Such high thermal inertia is indicative of a blocky terrain and lack of dust coating [41]. More detailed images and descriptions at the kilometer scale are deferred to Section 2.2, including the description of a swarm of small-scale fracture lines that may be significant for a better understanding of the nature of dendrites. 

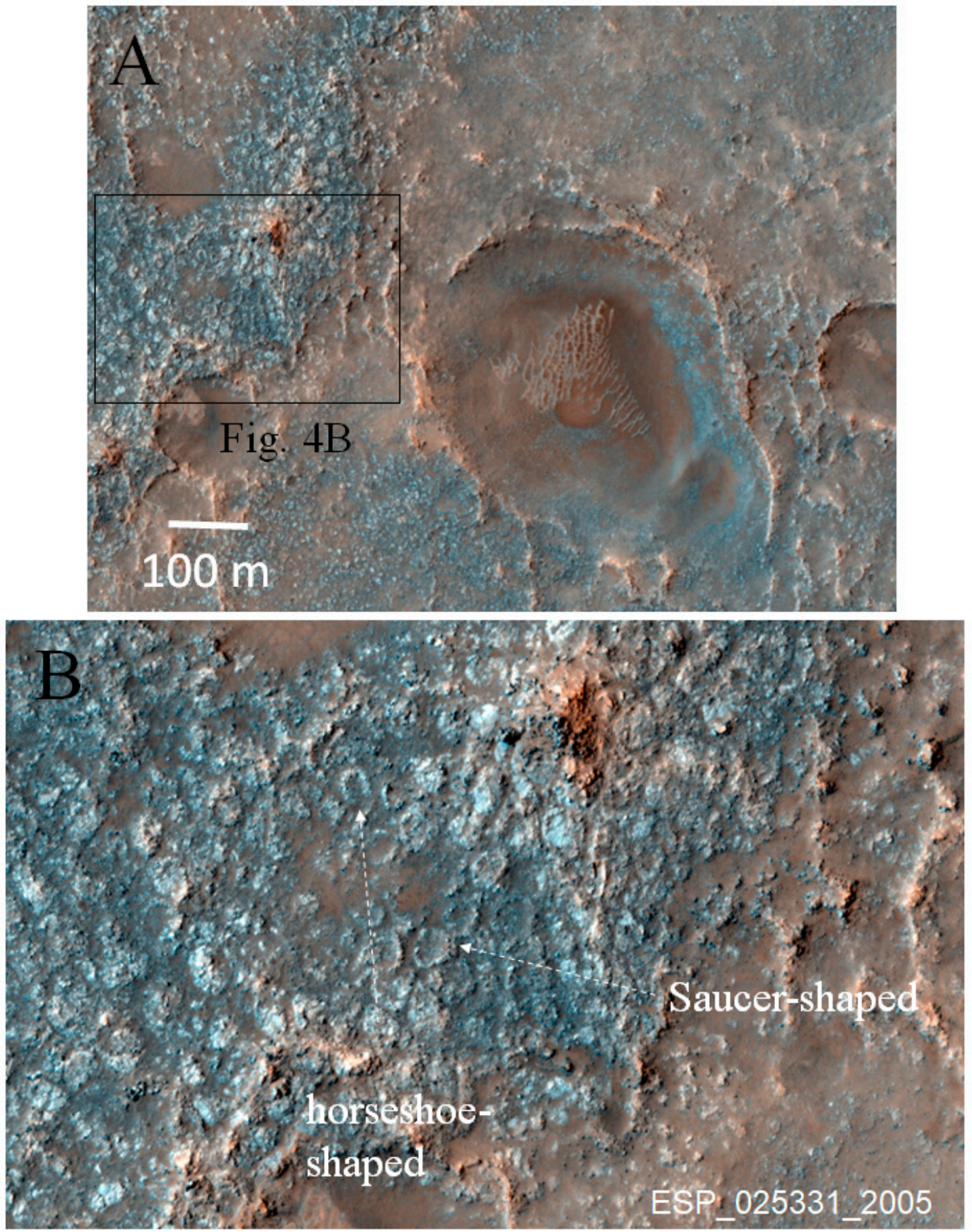

Figure 4. (A) This HiRISE image of the ESP_025331_2005 frame shows that the dendrites in the southeastern portion of the crater are made up of tabular units (most with subrounded outline), each approximately $15-18 \mathrm{~m}$ in size. The area in the rectangle is further enlarged in (B) to show that most of the tabular subunits are depressed in the center ("saucer-shaped") and some of them are horseshoe-shaped.

\subsection{Age of the Antoniadi Crater Bottom}

To better assess the chronology of the studied area, the diameters of impact craters were measured, and the resulting data analyzed with the Craterstats2 software [40,42]. In this analysis, age is provided by fitting the size-frequency cumulative curve of craters' diameters with appropriate isochrones tabulated for the proper rate of meteoritic fall onto the surface of Mars. The analysis is particularly significant for the largest craters of the 
given area, as the smallest ones are more easily affected by obliteration due to erosion or draping [40,42]. Three cumulative curves were produced (Figure 5A): (i) a first curve by counting all craters of diameter larger than $2 \mathrm{~km}$ inside Antoniadi, called "Area 1" in Figure 5A; (ii) a second curve was made for a smaller area within central Antoniadi that, in the present view, was occupied by the lake, selecting craters larger than $800 \mathrm{~m}$ (Area 2), and (iii) for comparison, a vast Noachian area northwest of Antoniadi was also selected, measuring the craters larger than $3 \mathrm{~km}$ (Area 3). Examination of the available HiRISE images shows that the ubiquitous windblown dust may have contributed to the draping of only the smallest craters, and thus probably does not affect age determination. Glacial and periglacial processes, lava flows, and ejecta blankets are more common at the periphery (Figure 1) and may, in particular, affect age determination of Area 2.
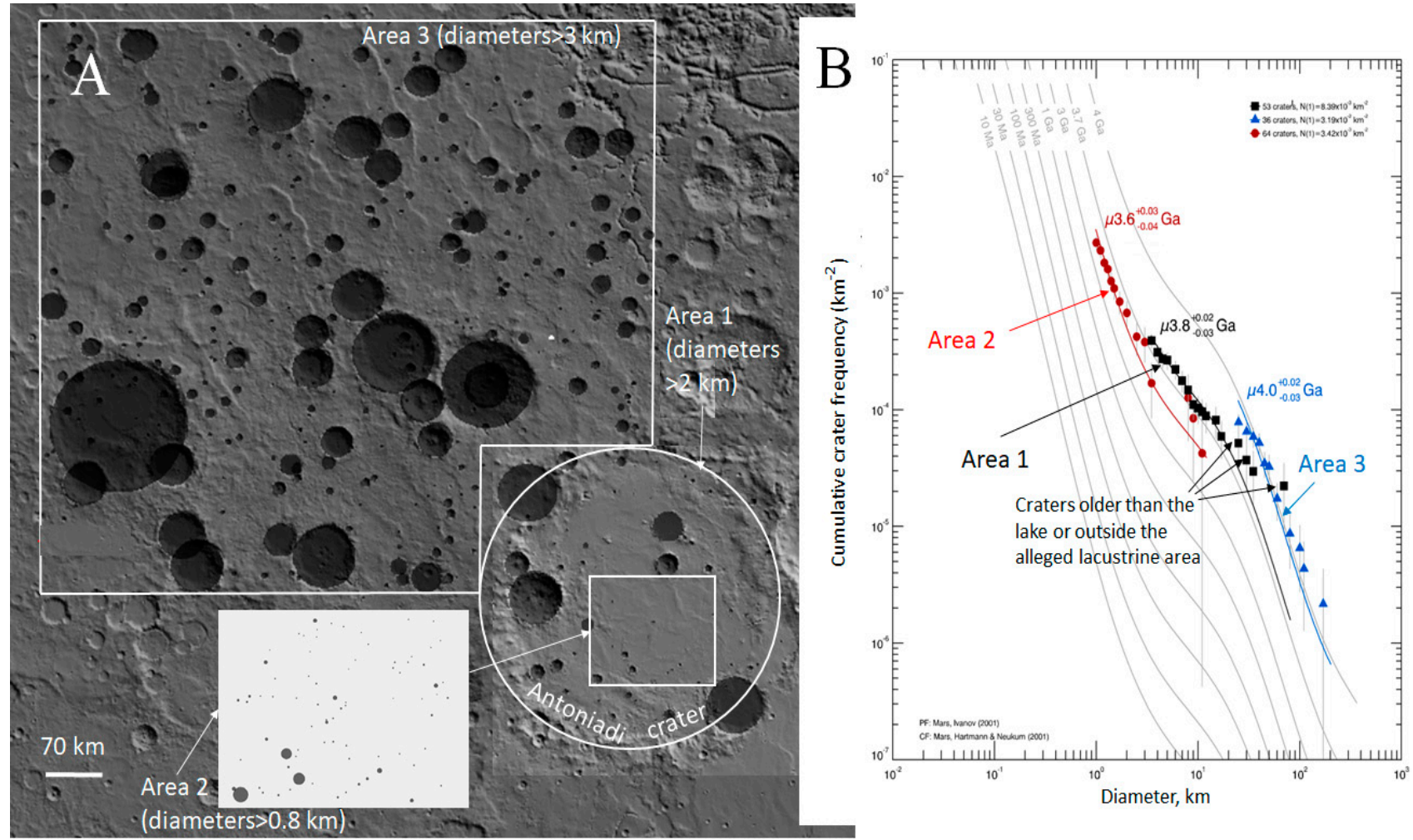

Figure 5. Dating of Antoniadi and surrounding areas. (A) The areas considered for age determination and the craters included in the analysis: "Area 1" inside the rim of Antoniadi (only craters larger than $2 \mathrm{~km}$ considered), a square in the central area of the crater ("Area 2", craters larger than $0.8 \mathrm{~km}$ ) and the area northwest of Antoniadi ("Area 3", craters larger than $3 \mathrm{~km}$ ). Crater counting is based on MOLA and CTX images on JMARS platform. (B) Results of the analysis performed with the software Craterstats2 [40]. The cumulative distribution for data from Area 1, 2, and 3 are shown with black squares, red circles, and blue triangles, respectively.

Figure $5 \mathrm{~A}$ shows the areas and the craters used for age determination. The results reported in Figure 5B (black squares) place the age of Antoniadi at about 3.8 Ga. Note that the presence of several large craters at the periphery of Antoniadi affects the global age in shifting the cumulative curve for large craters toward older ages. This part of the cumulative curve comprising craters older than the lake or outside the suspected lacustrine area is indicated with arrows. Thus, the inclusion of the whole area within Antoniadi gives somewhat an ambiguous result, as it implies the dating of two surfaces of different age. In fact, the age determined for the restricted Area 2 provides a younger age of 3.6 Ga (red circles). The age difference of approximately $200 \mathrm{Ma}$ between Antoniadi as a whole and the central unit results from the draping of craters in the central area, here interpreted primarily as lacustrine. Of the craters inside the alleged lacustrine area, probably only the very large 
one shown in Figure 1E predates the lake and is filled nearly to its rim (for this reason, this crater this has been excluded from Area 2).

In short, the lake lasted for about $200 \mathrm{Ma}$ after the impact that created Antoniadi at about 3.8 Ga. The age of the crater floor in central Antoniadi at about 3.6 Ga can be considered to correspond to the end of sedimentation of the ancient lake. The third dating concerns the neighboring area located NW of Antoniadi. The results shown as blue triangles in Figure 5B indicate an age of $4 \mathrm{Ga}$, confirming the Noachian age for the area [43]. Note how in this location, craters are statistically more common in a size class between 4 and $20 \mathrm{~km}$ compared to the largest craters of the order of $10 \mathrm{~km}$ within Antoniadi, which is understandable considering that the formation of Antoniadi has reset the age of the surface.

\subsection{Standard Interpretation of the Dendrites and Its Possible Difficulties}

Based only on the similarity to river networks on Earth and Mars, the dendrites could at first be interpreted as the remnants of past waterways similar to those of other locations on Mars [36] or groundwater sapping channels filled with erosion-resistant material [35], which, however, would require the presence of an aquifer. What is striking in this context is that the dendrites are inverted (i.e., in relief) on the alleged lake bottom (recognizable by the presence of the giant mud cracks in Figures 3 and 4). Note that lake desiccation is not the only process that may create polygonal ground on Mars, as periglacial processes are active on the frozen Martian ground especially at high latitudes (e.g., [44-46]). However, these also require the massive presence of ice, such as, for example, in the case of the Phoenix landing site [47]. Desiccation of Martian lakes is a process probably more common than previously thought [39,48]. One possibility invoked for other inverted river networks is that, after the river deposition, the lake was subject to wind or water erosion, with a significant inversion resulting from river sediments presumably harder than the soft clays of the lake bottom. Numerous cases of inverted relief are reported for both Earth and Mars $[12,36,49,50]$. However, as the mud cracks on the bottom of the Antoniadi crater are well preserved (Figure 3), the surface of the bottom appears as a pristine feature. This indicates lack of significant erosion on the floor after the lake disappeared. Even assuming that the river activity continued after the drying up of the lake, it is difficult to explain the sequence of events, as the river network should have (i) first eroded the bottom of the lake, after the lake had already dried up; (ii) deposited the load of dark sediments; and subsequently (iii) the bottom of the lake should have been eroded, leaving the dark dendrites in relief. The difficulty appears, above all, when considering that the bottom of the lake appears uncontaminated, implying that little material has been removed from the lake surface, thus making the sequence (i) to (iii) implausible.

A second puzzling feature is that the orientation of the dendrites is independent of the local slope gradient. Figure 6 shows the general geomorphological setting of the central dendrites with emphasis on the direction of the slope. For better explanation, the central dendrites have been, in turn, divided into a southern and a northern unit, with opposite orientation, separated by a linear central section. In the study area, the MOLA altimeter data shows elevation through sections $1-2-3$ and $1^{\prime}-2^{\prime}$ (Figure 6B), while dashed arrows show the local direction of descent at some selected locations. Overall, the data indicate that the descending gradient is oriented approximately from NNE to SSW. The high-resolution $(1 \mathrm{~m})$ digital terrain model based on HiRISE stereo pairs (a selected part of which is shown and commented on in the next section) confirms that the terrain descends along the NNE to SSW direction in the area of the dendrites. 


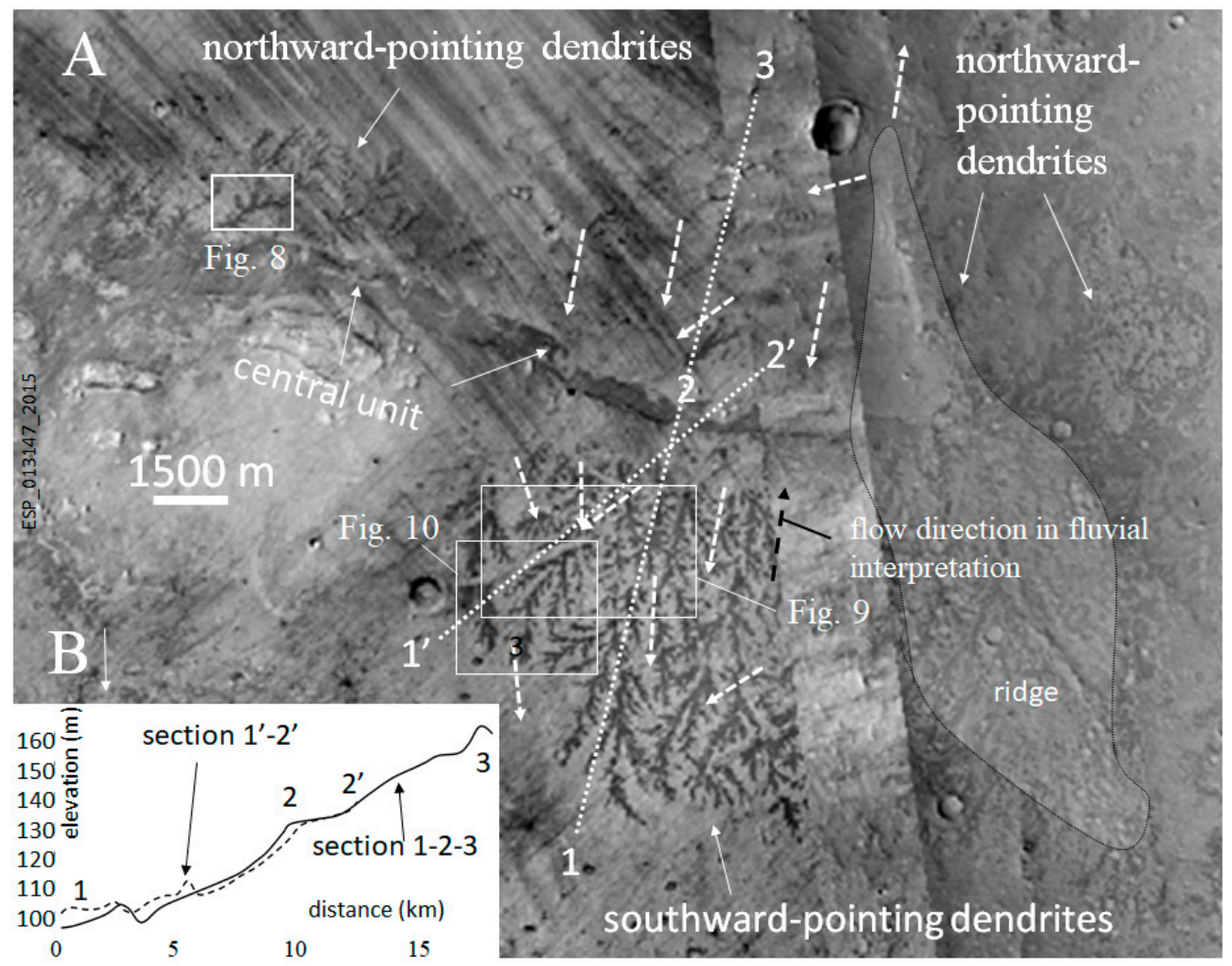

Figure 6. (A) Units recognizable in the central Antoniadi dendrites and relative slope gradient. The direction of the slope gradient at the selected locations is indicated with dashed arrows. The white rectangles are further expanded in the following figures. CTX mosaic. (B) Transects in MOLA elevation along sections $1-2-3$ and $1^{\prime}-2^{\prime}$ drawn in $\mathrm{A}$.

To better clarify this point, note that at the scale of few tens of kilometers, the remnants of direct or inverted ancient water flows on Mars (and also their direct counterparts on Earth, e.g., [36,50-52]) may be classified as (i) river networks deriving from precipitation and runoff in the drainage basin, often arranged in dendritic pattern [53]; (ii) alluvial fans due to discharge of water from a steep slope onto a flat subaerial area; (iii) deltas, when the water debouches into a water basin; and (iv) sapping channels due to discharge from an aquifer. Table 1 summarizes the properties of such ancient water flows which are diagnostic for the analysis. The table includes Martian and terrestrial examples for each of the four types, the possibility that two different branches may superpose, the characteristic slope, the possibility that branches be in relief with respect to the surrounding area, and the inferred direction of gravity. River networks incised by water precipitation and runoff (i) are characterized by a single tree-like geometry where one or few channels branch to numerous lesser, mutually-avoiding channels at higher elevation. There are no intersections for the reason that the prevailing branches convey all the water available to the basin and it becomes impossible for a new branch to develop at the expenses of the preexisting ones. Evidently, a river network implies water flow from the "branches" to the "stem", which also indicates the slope gradient if water precipitation ceases in the area. In contrast, both alluvial fans (ii) and deltas (iii) exhibit multiple, often braided, superposing distribution channels and are incised by water streaming from the "stem" to the "branches". In such cases, high water energy is concentrated in the upper reach of the channel, where a variation in discharge or local topography may reorganize the channels in numerous braided watercourses. Sapping channels (iv) observed, for example, along the outline of Valles Marineris, align to the local slope and to fault directions. In the same way as river networks, sapping channels tend to remain isolated. 
Table 1. Comparison between the patterns developed by riverine surface precipitation-runoff, delta and alluvial fans, groundwater sapping, biotic reefs, and the dendrites in Antoniadi crater. Data include references to some typical examples on Earth and Mars, superposition between branches, characteristic slope, the possibility that dendrites may form a relief, and the direction of gravity (from branches to stem or from stem to branches) that could be inferred without following terrain deformation. Characteristic slope data for deltas or alluvial fans (measured along the gradient direction) are from [15], while the other slopes for Mars have been measured with MOLA, taking a number of representative sections along the direction of the gradient.

\begin{tabular}{|c|c|c|c|c|c|c|}
\hline Type & $\begin{array}{c}\text { Example } \\
\text { (Earth) }\end{array}$ & $\begin{array}{c}\text { Example } \\
\text { (Mars) }\end{array}$ & $\begin{array}{c}\text { Superposition } \\
\text { between } \\
\text { Branches }\end{array}$ & $\begin{array}{c}\text { Characteristic } \\
\text { Slope }(\mathrm{m} / \mathrm{m})\end{array}$ & $\begin{array}{c}\text { Branches in } \\
\text { Relief? }\end{array}$ & $\begin{array}{c}\text { Inferred } \\
\text { Direction of } \\
\text { Gravity }\end{array}$ \\
\hline $\begin{array}{l}\text { Riverine } \\
\text { surface } \\
\text { precipitation- } \\
\text { runoff in } \\
\text { drainage basins }\end{array}$ & $\begin{array}{l}\text { Most river } \\
\text { drainages }\end{array}$ & $\begin{array}{l}\text { Some examples } \\
\text { on ancient } \\
\text { terrains } \\
\text { Warrego Valles } \\
\text { (Figure } 7 \mathrm{C} \text { ) }\end{array}$ & Absent & $\begin{array}{l}\text { Typically, } 1 / 50 \text { on } \\
\text { the large-catchment } \\
\text { areas on Mars. On } \\
\text { Earth, up to } 1 / 1 \text { in } \\
\text { the small } \\
\text { catchment areas at } \\
\text { high altitude down } \\
\text { to } 1 / 50 \text { in the } \\
\text { largest and lowest } \\
\text { ones }\end{array}$ & $\begin{array}{l}\text { Possible if the } \\
\text { water-carried } \\
\text { sediment is } \\
\text { compacted to a } \\
\text { deposit less } \\
\text { erodible than } \\
\text { the floor (e.g., } \\
\text { Figure 7A) }\end{array}$ & $\begin{array}{l}\text { Branches to } \\
\text { stem }\end{array}$ \\
\hline $\begin{array}{l}\text { Delta or alluvial } \\
\text { fan }\end{array}$ & $\begin{array}{l}\text { Many large } \\
\text { and small } \\
\text { rivers }\end{array}$ & $\begin{array}{l}\text { Numerous } \\
\text { examples (e.g., } \\
\text { Figure 7B) }\end{array}$ & $\begin{array}{l}\text { Common } \\
\text { (braided) }\end{array}$ & $\begin{array}{l}1 / 20 \text { to } 1 / 10 \text { (up to } \\
\frac{1}{2} \text { for the } \\
\text { submerged part in } \\
\text { Gilbert-type deltas); } \\
\text { On Earth, } 1 / 40 \\
\text { to } 1 / 2\end{array}$ & $\begin{array}{l}\text { Possible if } \\
\text { carried } \\
\text { sediment } \\
\text { harder than } \\
\text { floor (e.g., } \\
\text { Figure 7B) }\end{array}$ & $\begin{array}{l}\text { Stem to } \\
\text { branches }\end{array}$ \\
\hline $\begin{array}{l}\text { Groundwater } \\
\text { sapping }\end{array}$ & $\begin{array}{l}\text { Grand } \\
\text { Canyon }\end{array}$ & $\begin{array}{c}\text { Numerous } \\
\text { examples in } \\
\text { Valles Marineris }\end{array}$ & Mostly absent & $\begin{array}{l}1 / 50 \text { to } 1 / 8 \text { (Valles } \\
\text { Marineris); up to } \\
1 / 10 \text { on Earth (e.g., } \\
\text { Grand Canyon) }\end{array}$ & Not known & $\begin{array}{l}\text { Branches to } \\
\text { stem }\end{array}$ \\
\hline Biotic (Earth) & $\begin{array}{l}\text { Stromatolite } \\
\text { reefs }\end{array}$ & Unknown & $\begin{array}{c}\text { Possible on } \\
\text { dead branches }\end{array}$ & $\begin{array}{c}\text { Virtually null } \\
\text { (parallel to shore), } \\
\text { to } 1 / 20 \\
\text { (perpendicular to } \\
\text { shore) }\end{array}$ & $\begin{array}{c}\text { Occurs } \\
\text { naturally }\end{array}$ & $\begin{array}{l}\text { Growth } \\
\text { possible in } \\
\text { both ways }\end{array}$ \\
\hline Antoniadi & & $\begin{array}{l}\text { Possible } \\
\text { microbialite } \\
\text { reefs? }\end{array}$ & $\begin{array}{l}\text { Observed, but } \\
\text { uncommon }\end{array}$ & Less than $1 / 200$ & Yes & $\begin{array}{l}\text { Growth } \\
\text { possible in } \\
\text { both ways }\end{array}$ \\
\hline
\end{tabular}

Figure 7 shows selected Martian examples of the different remnants of water flows on Mars. While Figure 7A shows a precipitation-runoff river network, Figure 7B illustrates an example of compound alluvial fan resulting from the migration of multiple streams. Figure 7C shows Warrego Valles, another example of a dendritic precipitation-runoff river network. This geometry, being the probable result of the precipitation of water collected over a large area and surface runoff conveyed into a main river, indicates a movement of water from many to fewer branches, confirmed by the downhill gradient (arrow). In addition, gullies due to the process of groundwater sapping indicate the movement of water from many to few branches. 

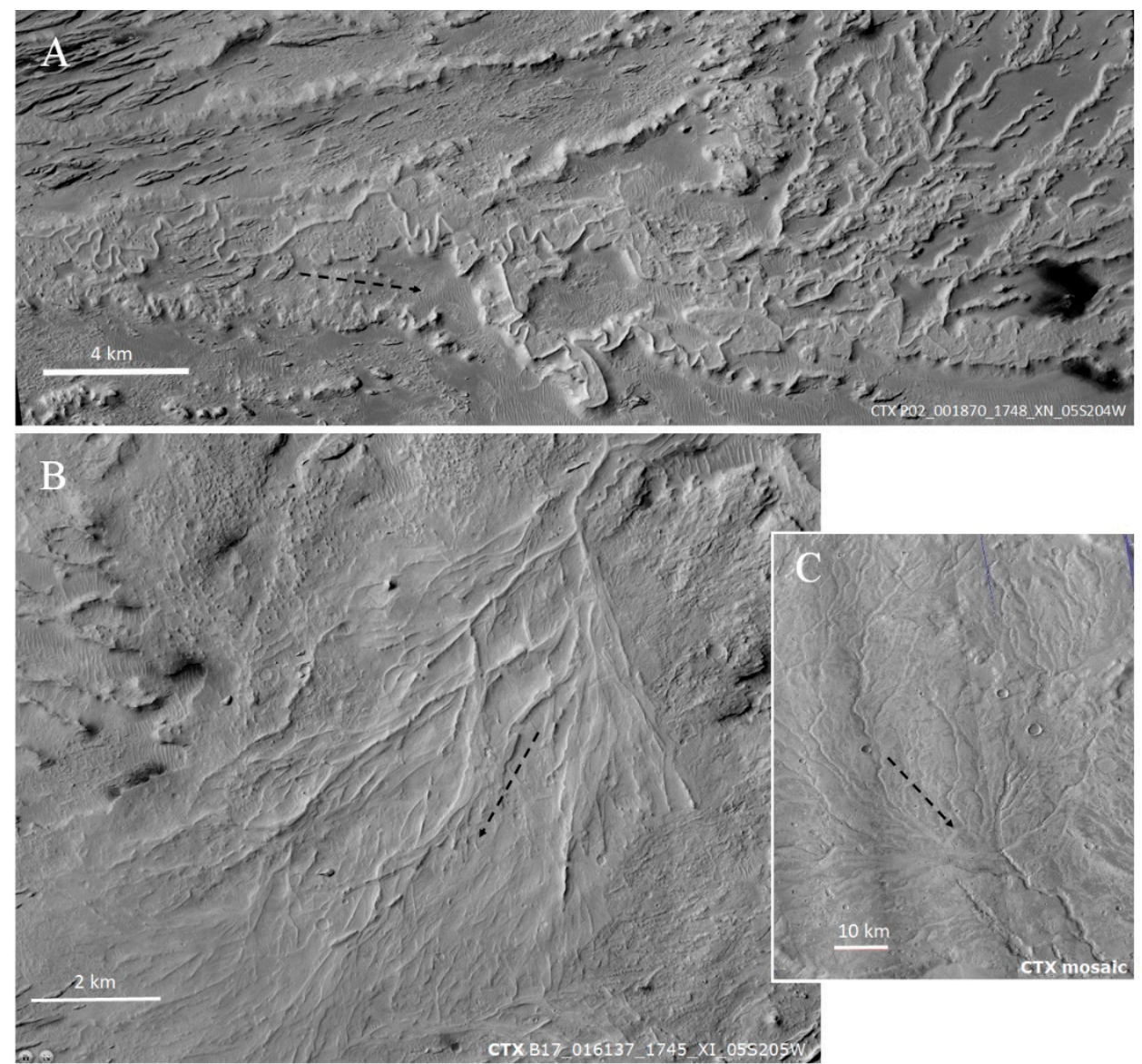

Figure 7. (A) Example of an inverted river channel on Mars located at 348.6 E, 7.7 N, approximately $130 \mathrm{~km} \mathrm{NNW}$ from the rim of Crommelin crater due to water precipitation and runoff. The direction of flow indicated with an arrow points from the area of multiple "branches" to the "stem". (B) An example of a "complex" inverted delta fan on Mars located in the area between the Asau and Kalba craters $(930 \mathrm{~km}$ east of the Gale crater) in Aeolis Mensae, indicating a delta deposition and flow direction from the "stem" to "branches". (C) Warrego Valles, a dendritic river network system indicating surface runoff due to precipitation over a large area. CTX images. The descending gradient is indicated with a dashed arrow in each image.

Contrary to the case in Figure 7B and in agreement with Figure 7C, if the dendrites in Antoniadi resulted from the fluvial action, they were not alluvial fans or deltaic (as the observed dendrites are not braided), but resulted from the precipitation of water, which then must have flowed from the branches to the stem. Thus, if the dendrites are to be interpreted as the product of a local exhumed river network, the south-facing units are directed in the opposite direction, indicating that the water flow apparently travelled against the slope. In other words, the mentioned orientation of the river network (compare Figures 6 and 7B) becomes problematic. An answer could be that local changes in slope may have occurred following the placement of the alleged river network at Antoniadi, especially in consideration of the volcanic nature of the area. In a different region, the weight of the giant volcano Olympus Mons, for example, caused a noticeable flexural deformation in a large area of Tharsis [54], locally reversing the slope. An example of slope inversion of a surface previously carved by water flow was reported in [55] for an area along the dichotomous line, where river deltas of the "birdfoot" type point in the opposite direction to what the morphology would suggest. Thus, in principle it is possible that the network in Antoniadi was created with the correct orientation proper to precipitation-runoff riverine erosion and was subsequently deformed by structural and (or) volcanic-plutonic processes. In addition to local loading, global tensional fields across the 
Martian lithosphere also indicated by the occurrence of pressure ridges throughout Mars may have played a role [56,57], and this area is no exception (one large ridge of probable structural origin appears in the field of Figure 6). Therefore, the argument exposed here of the "wrong" dendrite orientation cannot conclusively prove the nonriverine origin of the dendrites. Early Mars shows a complex tectonic history on a global scale [57], which leaves the possibility that the terrain within Antoniadi was tilted after the lake disappearance. Still, one would expect a post-crater uplift in the southern part of Antoniadi where Syrtis Major stands, which increases, rather than solves, the problem of the wrong dendrite orientation. A perhaps stronger argument against the interpretation of dendrites in Antoniadi as erosion and accumulation-produced topographic features is that, as shown in Table 1, the characteristic slope of water processes on Mars is much different from those of Antoniadi dendrites.

Water processes on both Mars and Earth occur on terrains that typically exhibit a certain gradient range. Measured slopes are on the order of $1 / 50 \mathrm{~m} / \mathrm{m}$ for surface runoff in the drainage area (e.g., Warrego Vallis), between $1 / 20 \mathrm{~m} / \mathrm{m}$ and $1 / 10 \mathrm{~m} / \mathrm{m}$ along alluvial fans or deltas (if the fan is built in lacustrine area, the part of the delta in contact with water is much steeper), and $1 / 50 \mathrm{~m} / \mathrm{m}$ to $1 / 10 \mathrm{~m} / \mathrm{m}$ for water sapping channels, as measured in Valles Marineris. Note that although the slopes on Earth are comparable to those on Mars, more extreme cases are found for the terrestrial case where smaller features are more common than on Mars (the steepness has an inverse relationship with size). In contrast to such typical steepness, the dendrites in Antoniadi occur on a much gentler area, of slope less than $1 / 200$. Invoking a flexural deformation would require a slope variation of the terrain initially sloping at, say, $1 / 20$ to one tenth that amount (or even slightly negative in some areas, as discussed earlier). Although many other factors, such as infiltration, may affect the slope of the riverine processes, this tilt of exactly the necessary magnitude to bring a steep slope to a much flatter area appears unlikely. The virtually flat area in the center of Antoniadi can be better explained simply as reflecting the typical (and undeformed) steepness in the center of the large craters on Mars, especially if filled with smoothing material. As a further argument, in the next section, some sporadic cases of overlapping of distinct branches can be identified, which are incompatible with the processes of runoff or sapping processes.

\section{Possible Alternate View for Dendrites within the Antoniadi Crater}

\subsection{Microbialite Interpretation}

Might the dark dendritic patterns in Antoniadi be the expression of microbialitic structures rather than riverine processes? Even though it is not possible to come to a firm conclusion without a rover exploration, the discussion will hopefully be useful in indicating Antoniadi as a possible interesting target for future astrobiological missions. Not having access to a set of rover data, the arguments exposed here will be necessarily based on largescale morphology. Microbialites on Earth, such as stromatolites, exploit water circulation, forming reefs from cementing grains of the available rock or carbonate precipitation [58-62]. Because of the impossibility to refer specifically to any precise typology of microbialite as we know it on Earth, in the following we loosely refer to the allegedly biological morphologies in Antoniadi as "microbialite" or "stromatolite".

Many authors have stressed that extinct lakes may be the best places to search for ancient life on Mars, especially if warmed by local magma in analogy with terrestrial hot springs [63-65], terrestrial lakes [66], and lakes filling impact craters on Earth [67]. Stromatolites give rise to endured grow edifices that are typically smaller than the units in Antoniadi [68], but tabular, enormous stromatolitic buildings are known on Earth, for example, the Eocenic Green River Formation of Colorado [69]. One critique to the interpretation of dendrites in Antoniadi as possible stromatolite reefs is that, even though some areas on Earth display stromatolites distributed along kilometers-wide areas (e.g., [70]), large stromatolite reefs are uncommon. However, it is well known that the growth of stromatolite reefs today is limited by grazing organisms feeding on them. In fact, there is evidence that 
stromatolitic reefs covering vast areas may have been commonplace in the Precambrian [71] Another fruitful comparison can be made with other terrestrial biotic structures such as coral reefs, which often develop branches on the kilometer-scale (e.g., [72]). Although terrestrial coral reefs are obviously made up of more complex and evolved mutualistic communities than microbialitic reefs, the growth of both communities is essentially based on the availability of some important limiting factors, i.e., (i) light, (ii) waterborne suspensions, which consist of food for corals, and rock particles for microbialites, (iii) biotic interactions such as grazers in terrestrial environments [73], (iv) redox gradients, and (v) radiation shielding (for Mars).

If the tabular constructions in Antoniadi are the result of water-related biotic activity, their relief from the lake floor would be explained as the result of biotically-induced entrapment of sediment. Notice that although most Precambrian stromatolites grew by fixing carbonates, and even if lacustrine carbonates have been documented for at least the Jezero crater [74], carbonates are not essential to the build-up of stromatolite edifices [75]. Cyanobacteria will entrap the material available regardless of composition, as demonstrated by the relative commonness of stromatolite reefs mostly composed of volcaniclastic grains [68].

\subsection{Further Morphological Evidence in Favor of the Microbialite Interpretation}

A significant feature of some of the tabular units in Antoniadi is their concave-up orientation (i.e., most of them appear saucer-shaped, and some horseshoe-shaped), particularly those that make up the eastern dendrites. Figure 4B shows in detail such tabular units, some of which are marked with an arrow. Composite biological assemblies often expand in ring-shaped morphologies as a consequence of deterioration in the center, where the nutrients or the substance necessary to cement the structure are scarce. The circular assemblies in Lake Thetis are an example of ring-shaped microbialitic constructions [76,77]. In addition, more evolved sessile communities in water or on land, such as microatolls [78] or fairy circles, made up by some species of fungi or bushes in grassland (e.g., [79]), grow following the same centrifugal pattern due to decline of nutrients in the center caused by biotic (competition) or abiotic (e.g., wind) effects. The similarity of such bioticallyrelated processes leading to saucer-shaped elements and the tabular units in Antoniadi is interesting, but by no means represents evidence of its biotic nature. As an alternative, such concave-up features in Antoniadi may be the result of drying after the demise of the lacustrine water. Terrestrial evidence shows curling-up of the edges in clay-rich drying lacustrine units [80-82]. However, considering that the tabular units in eastern Antoniadi are much wider than the terrestrial counterparts, which are typically decimeters wide, curling-up is probably not the most important mechanism shaping the tabular units, even considering the different gravity between Earth and Mars.

\subsection{Dendrites on Kilometer-Size Scale and Small-Scale Faults}

Another puzzling feature concerns the shape of the dendrites on the scale of $1 \mathrm{~km}$ or more. First, they tend to increase in width as they branch, which is opposite to what could be expected in river networks or groundwater sapping processes (Figure 8). Furthermore, some dendrites were interrupted by fractures inside the crater floor. Some examples are shown with dashed lines in Figure 9B (noninterpreted image in Figure 9A). 

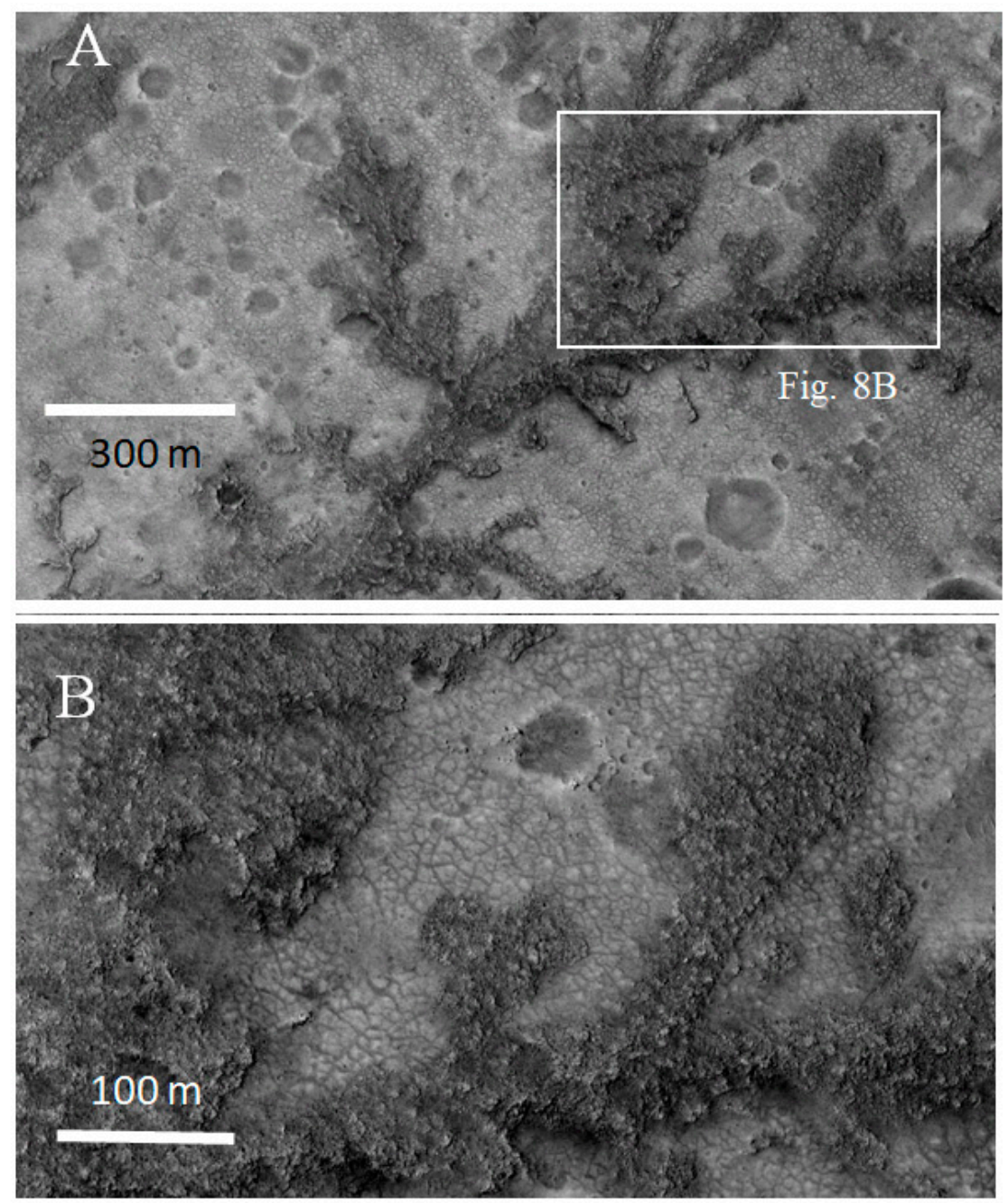

Figure 8. (A) Example of dendrites increasing in width with distance from the branching point. The area is shown as a rectangle in Figure 6. (B) Magnified version of the image in A. CTX images.

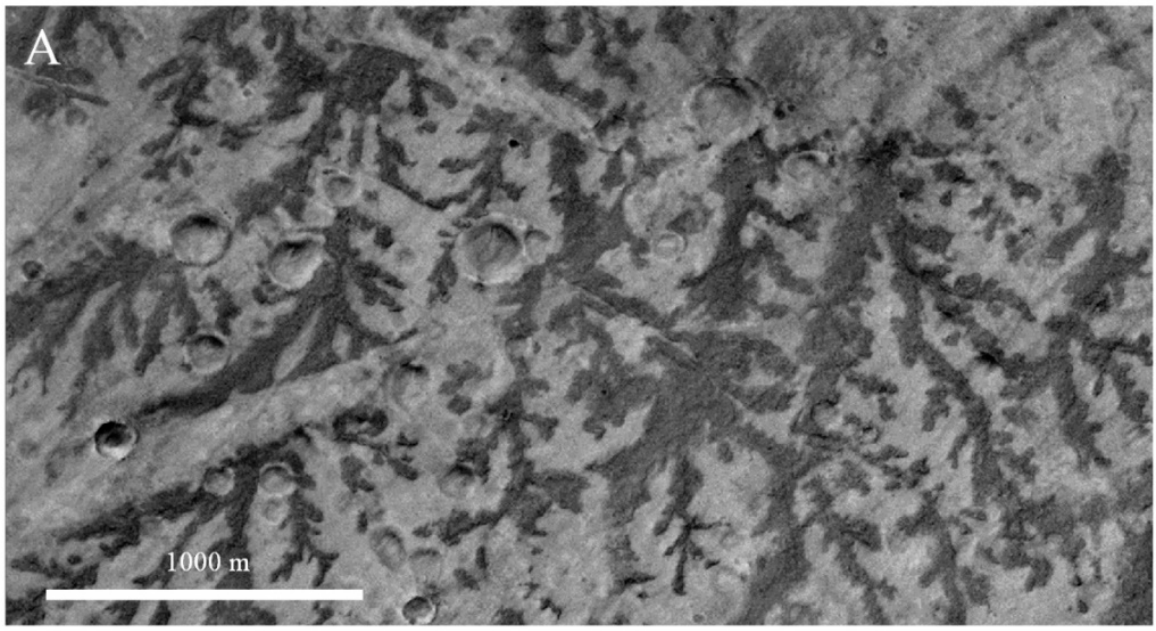

Figure 9. Cont. 


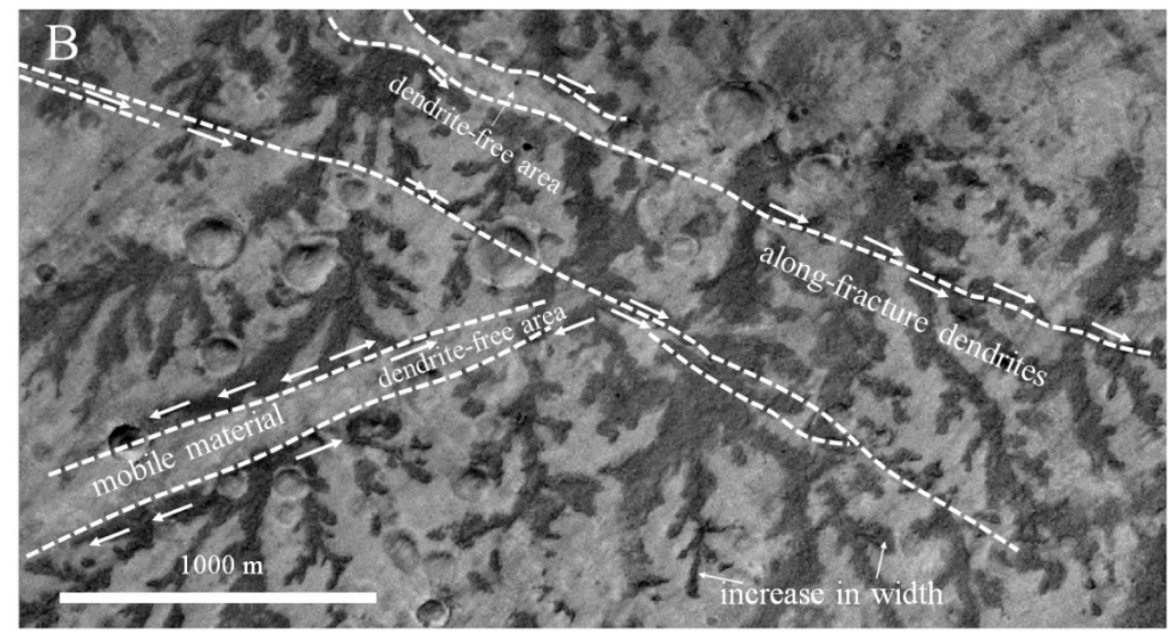

Figure 9. (A) Detail of the area marked with a white rectangle in Figure 6. (B) Interpreted image of the same area showing the faults, along-fracture dendritic growth, and dendrite-free spaces. CTX images. At the locations indicated with arrows, dendrites appear to follow the fracture (fault) lines, indicating the possibility that, after being separated by a fracture line, the dendrites subsequently propagated parallel to the fracture ("along-fracture dendrites" in Figure 9B).

Note that some of these fractures may be likened to direct faults and imply a splitting between parallel fracture lines. The presence of these faults could corroborate the geobiological explanation compared to the fluvial one. To understand this point, first note that it is possible to recognize at least two types of interfaces between truncated dendrites and fractures. The first type is characterized by the area between parallel fractures partially invaded by some sort of mobile material, probably fine sediments at the lake bottom, here loosely referred to as "lake mud" (Figure 9B). This is evident from examination of the HiRISE DTM map, where this area between fractures appears as a ridge, rather than a depression (Figure 10A,B). Note that in these locations, the dendrites abruptly interrupted by fractures are elongated along the border with the mobile material (arrows in Figure 9). This implies that after being separated, the dendrites have grown parallel to the fractures themselves. Such growth may have occurred after the gap between fractures became filled with the mobile material, which would be inconsistent with riverine of sapping processes. Closer images are also presented in Figure 11. Note the apparent lining up of the dendrites as if to follow the edge of the mobile material. In the case of Figure 11B, the dendrite seems to avoid one of the two craters that were probably already in place before the dendrites englobed them. 

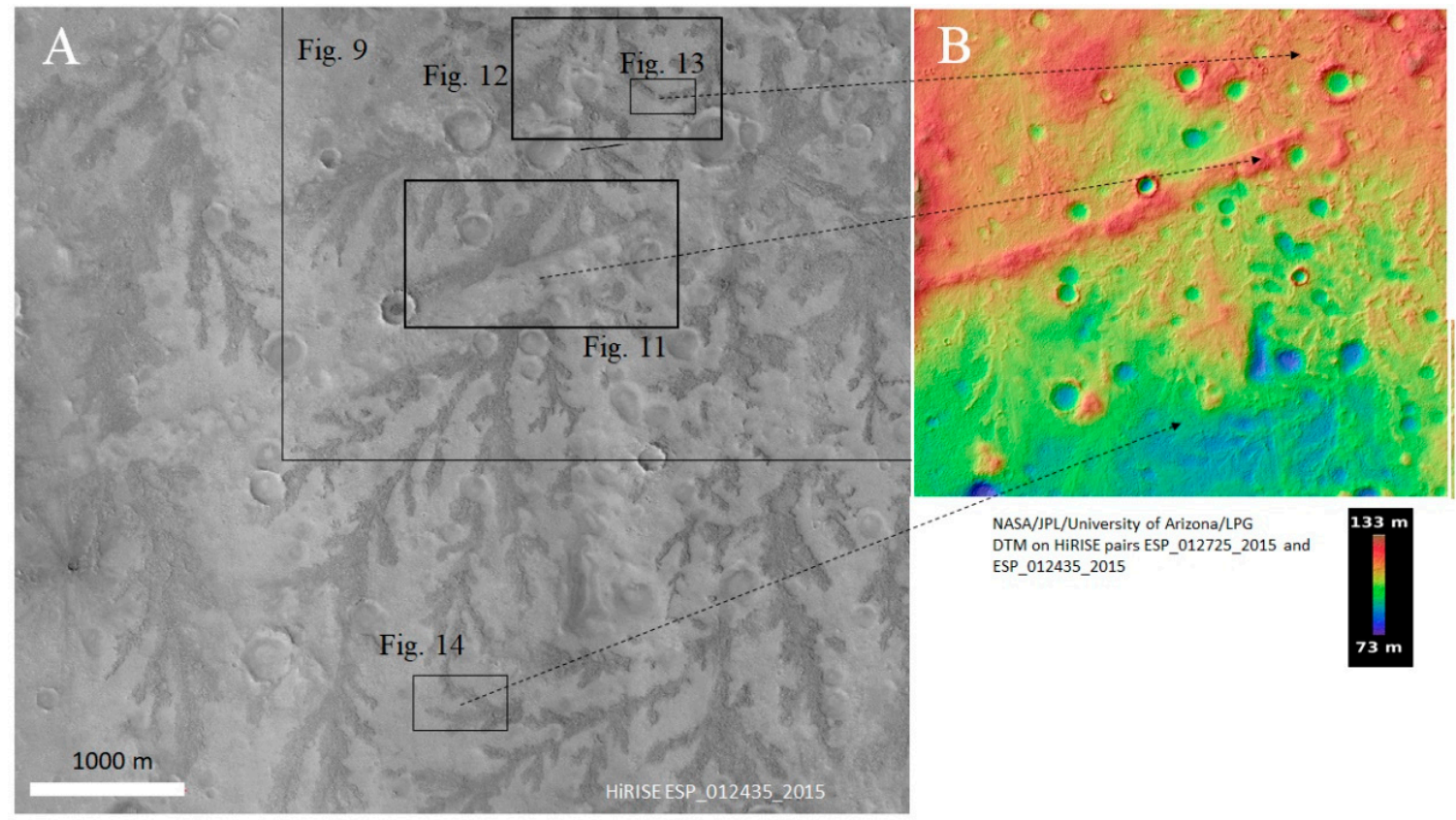

Figure 10. (A) HiRISE image of the central part of the dendrites (the area shown here is marked in Figure 6A). (B) DTM of the same area based on wider image released by the Lunar and Planetary Laboratory of the University of Arizona based on HiRISE stereo pairs ESP_012725_2015 and ESP_012435_2015 (https://www.uahirise.org/dtm/dtm.php?ID=ESP_012725_2015, accessed on 31 July 2020).

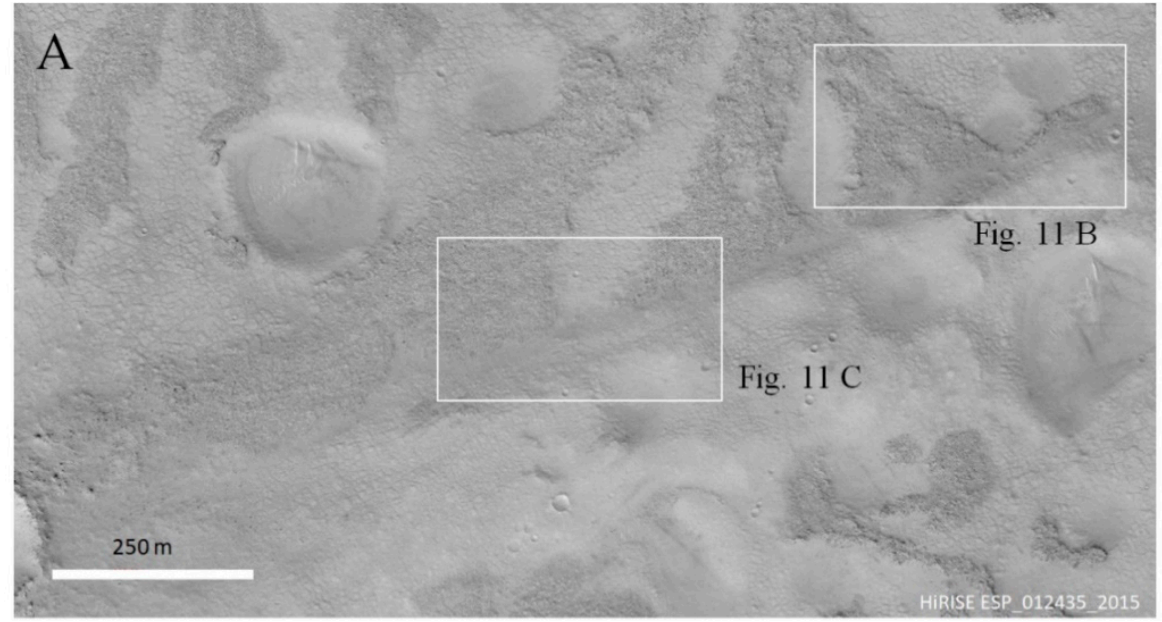

Figure 11. Cont. 

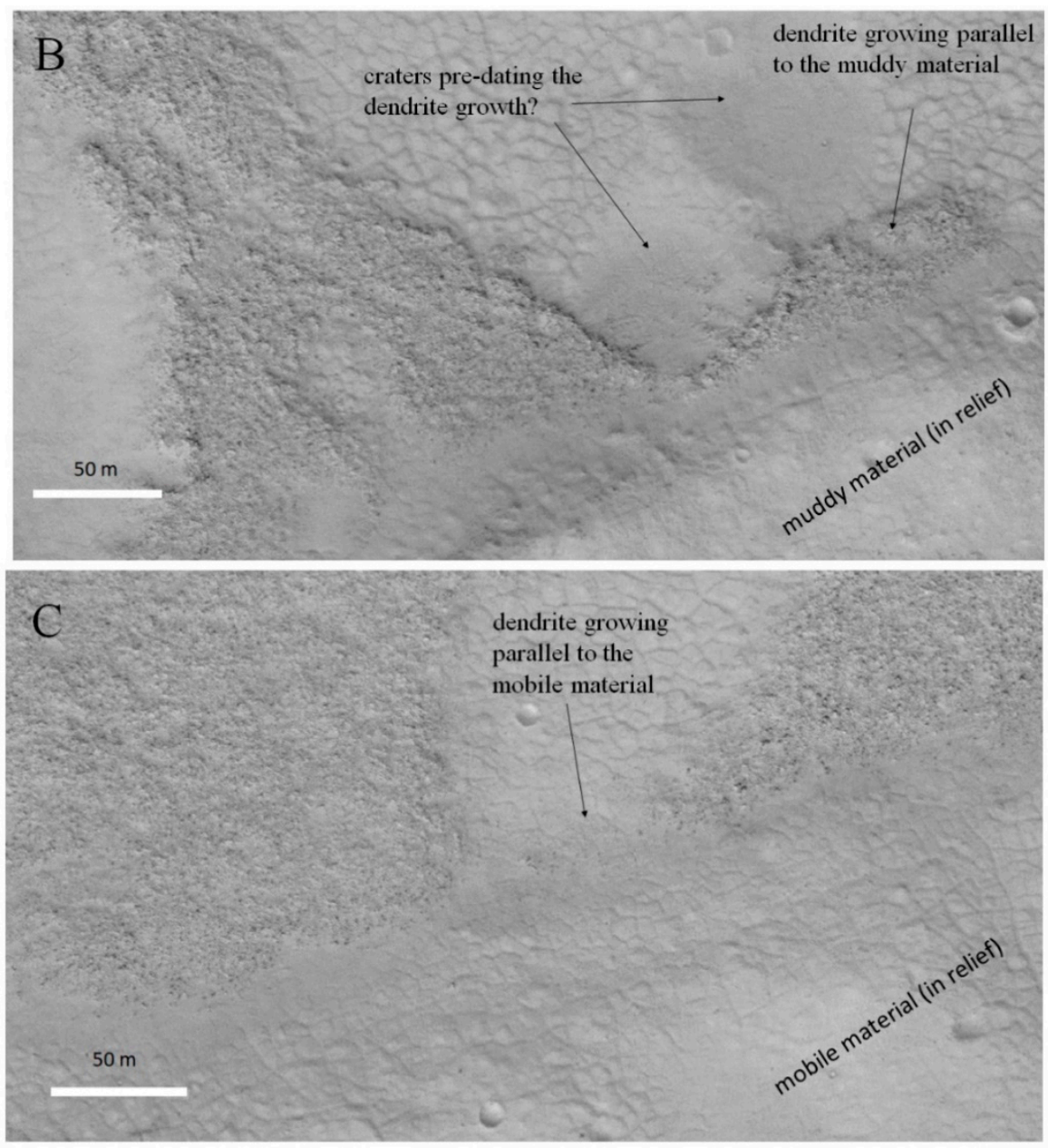

Figure 11. (A) HiRISE details of dendrite growth parallel to the mobile material. The area examined is highlighted in Figure 10. (B,C) Details of growth along the deposit of mobile material, probably consisting of lake mud.

In a second type of fault-dendrite interface, the gap between the faults, rather than being raised, has lower elevation with respect to the adjacent area, and therefore the mobile material is absent or depressed. One of these features is examined in detail in Figure 12 (location map in Figure 10). Note first the initial southward propagation of the dendrite (which in the present interpretation would imply a previous growth before coming into contact with the fault line), and further eastward propagation along the fault. This particular case presents the further key feature of dendrite superposing with an earlier dendrite from a different branch. Figure 13 shows in more detail the area within the rectangle of Figure 12, and the insert in Figure 13B illustrates the inferred sequence of overlap (stratigraphic scheme in Figure 1E). Another case of overlap is shown in Figure 14 (location map in Figure 10). In this second case, a jumbled superposition area (shown in black) makes it difficult to tell which part of the superposed part belongs to which of the two branches. Such overlapping features are enlightening, as both sapping and nondeltaic riverine channels (Figure 7C) are mutually-avoiding and do not typically cross each other. Note also the bridge in Figure 12 which apparently grew between the parts of the dendrites that had previously been separated. These characteristics can best be explained as overlapping growing branches. 


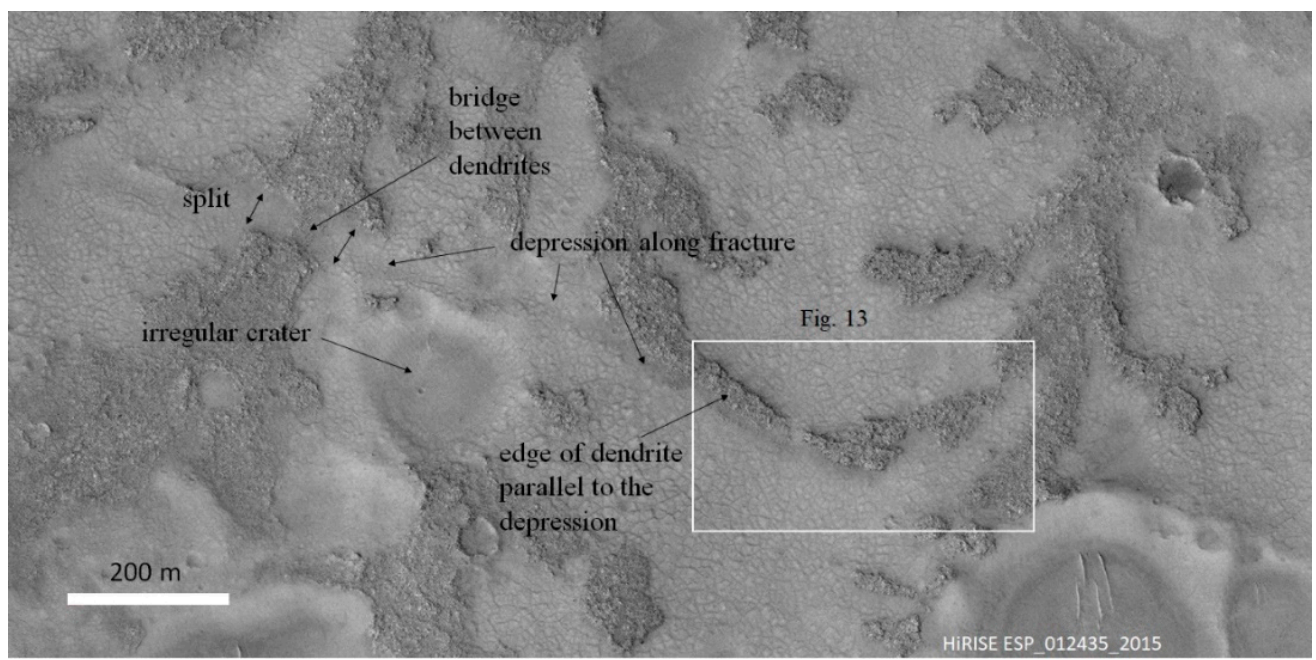

Figure 12. HiRISE detail of a $400 \mathrm{~m}$ long dendrite branch parallel to a shallow depression probably linked to an earlier fracture ("edge of dendrite parallel to the depression"). To the left, a bridge between dendrites may have been formed after split of the pre-existing dendrite by the fracture, as indicated in the figure. One of the many irregular (i.e., not perfectly circular) craters, probably created when the lake was still present, is indicated with an arrow. It is suggested that the impact that produced the crater shattered a portion of the dendrites. Note the intact dendrite, especially in the southern end of the impact crater. Two remnants of the dendrites are also visible on the upper left and right of the crater. The area shown here is marked in Figure 10.

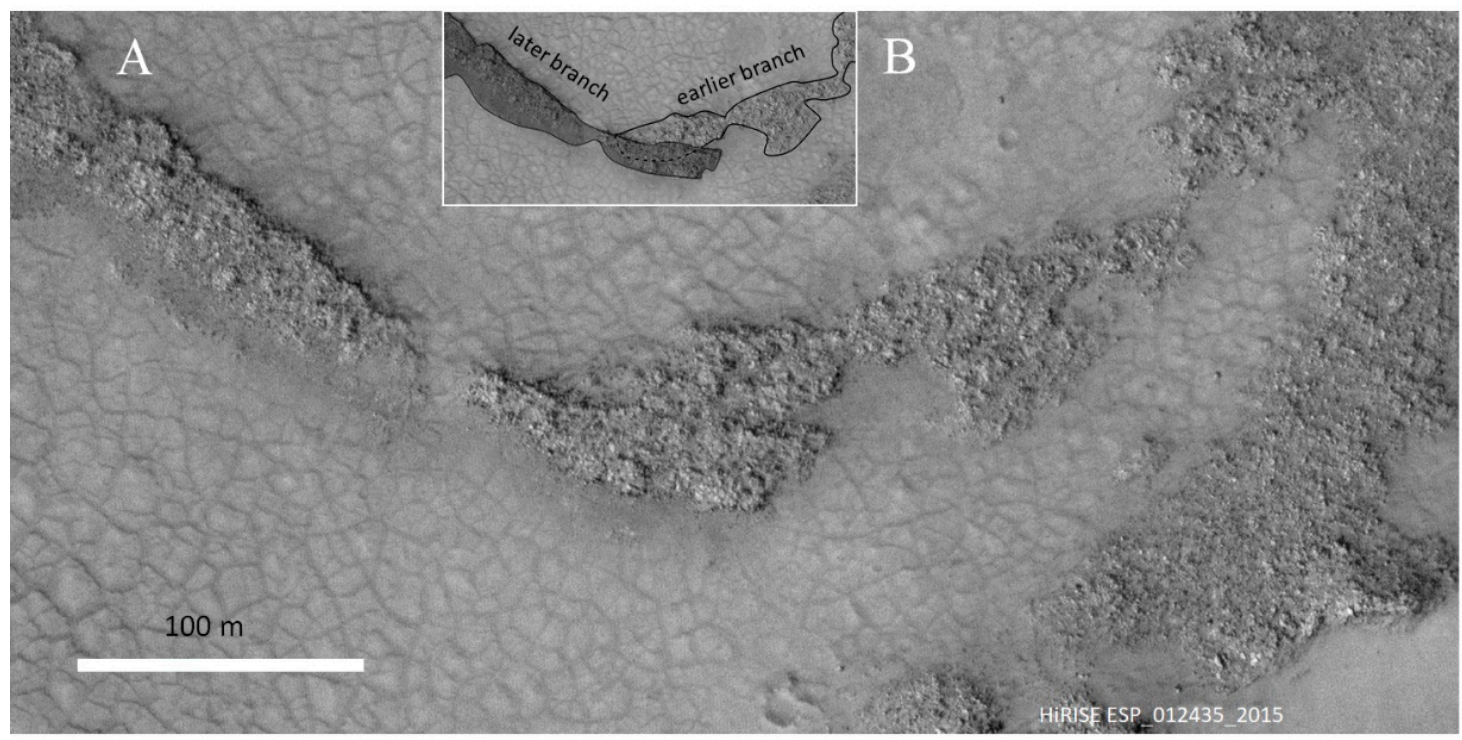

Figure 13. (A) Detail from Figure 12 showing the superposition between two different dendritic branches. (B) The interpreted order of superposition. 


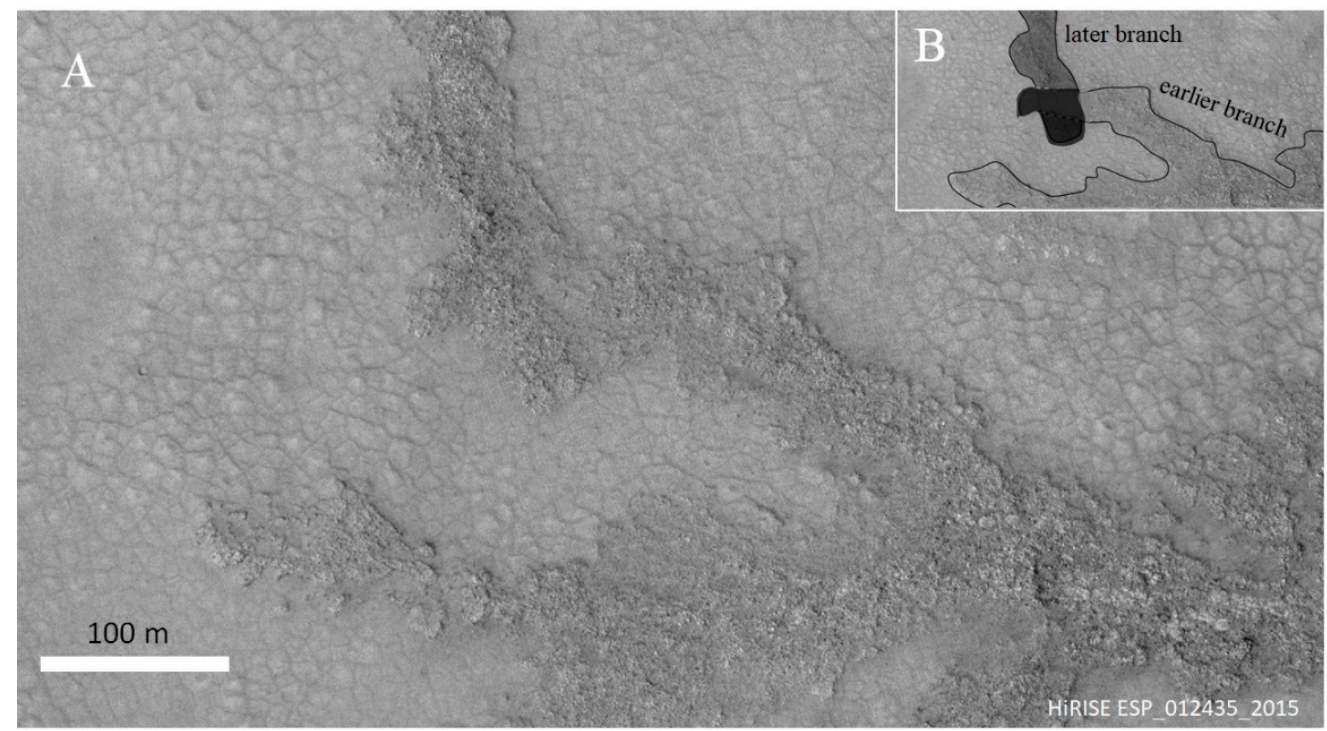

Figure 14. (A) Another example of superposing dendritic branches. (B) Interpreted order of superposition. The area shown here is marked with a rectangle in Figure 10.

Figure 15 summarizes the inferred evolution of the area selected in Figure 12. The initial growth of different branches (Figure 15A) is followed by faulting in B (without, in this case, any flowage of mobile material between the faults in the depressed area), and regrowth of dendritic material (C). Finally, the growth of the younger branch parallel to the fault line partially covered an older one (D). Also noteworthy is the impact crater in the area of the figure that clearly removed part of the dendrites.
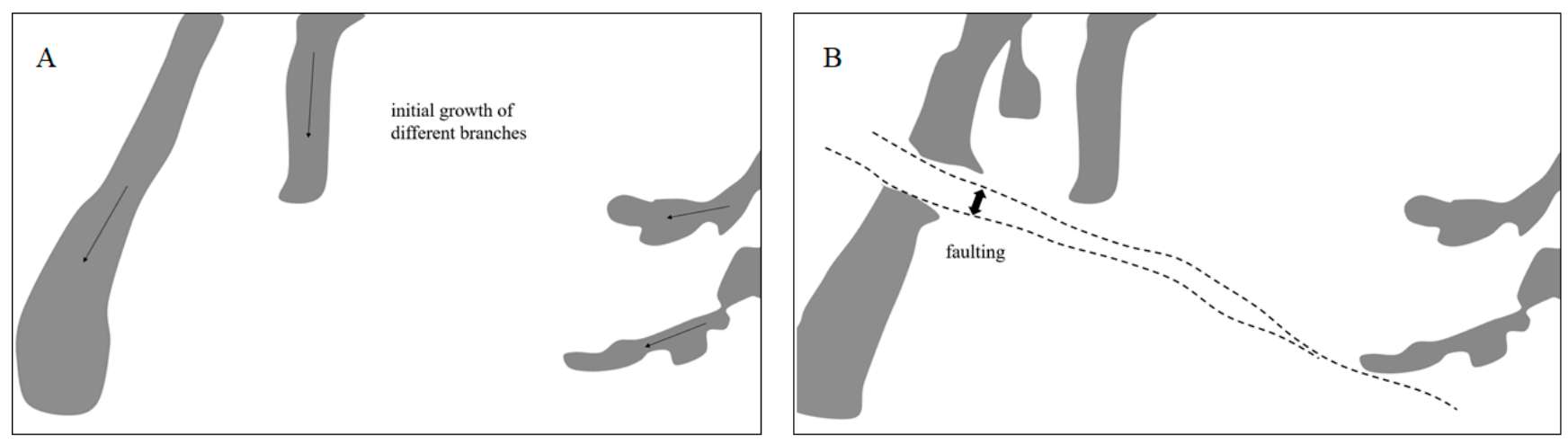

Figure 15. Cont. 

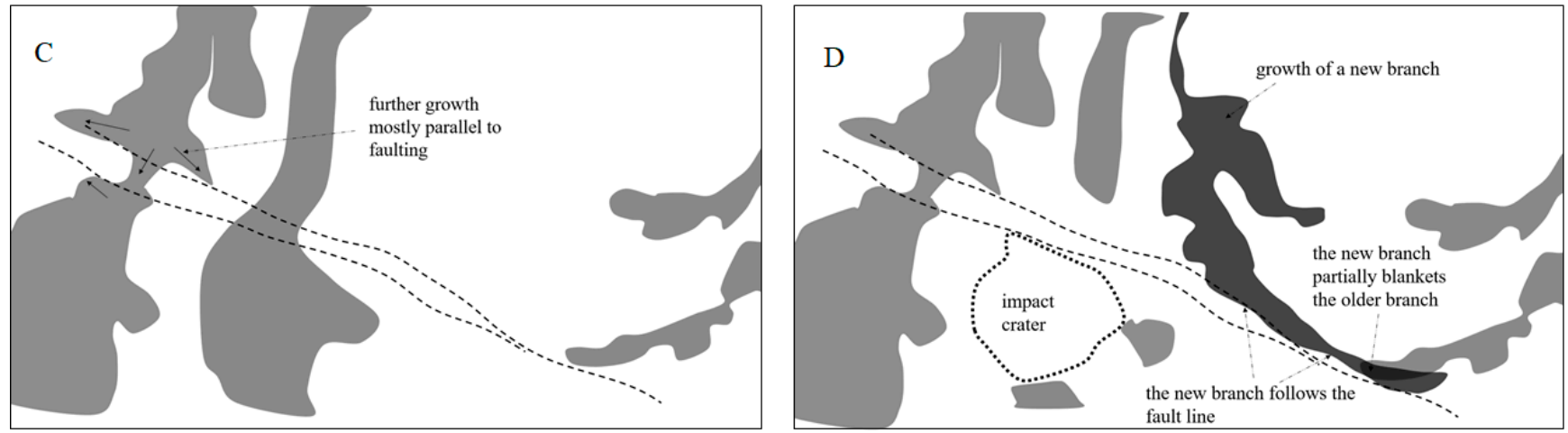

Figure 15. Interpretative scheme of the evolution of the area shown in Figure 12. (A) Initially, dendrites have grown from different branches. (B) Faulting occurs and some branches are split up. (C) Further growth occurs parallel to the fault lines; in addition, a bridge between the edges of previously separated dendrites is created. (D) A new branch develops and propagates parallel to the fault line, ending up superposing to a previous branch.

Figure 16 outlines the four basic growth patterns examined earlier that indicate stem-tobranch dendritic growth and may be incompatible with riverine, deltaic, and groundwater sapping processes. A1-A2 shows the suggested evolution of one dendrite growing sideways over time (see Figure 8). B1-B4 outlines the growth progression interrupted by the faults, the gap filled with mobile material (B5), and then re-growing parallel to both the fracture lines and the deposit of the mobile material (B6). C1 and C2 show the effect of one branch overlapping a previous one. D1-D3 display the effect of fractures splitting a dendrite in two as in B1-B6, this time without mobile material filling the gap. In this case, further growth parallel to the fault also occurs, and post-separation can form a bridge between the two dendrite parts that were previously united. These patterns may be more difficult to explain in terms of water flow processes. If the dendrites were the product of dark sediment carried by water, such processes were already ended when the sediments were deposited and the mud eroded away, leaving the more resistant dark sediments. There is no obvious process that may have remobilized these sediments to form the new patterns, such as bridges, or make them grow parallel to the faults. A possible physical explanation for the bridge is the sliding of the dark material into the depression once the two parts of the dendrite were separated. However, the estimated slope from one of the edges to the bottom of the depression based on the HiRISE DTM (Figure 10B) is only $1 / 10 \mathrm{~m} / \mathrm{m}$ or $5.7^{\circ}$. Although such a flow process cannot be ruled out, the slope is probably not sufficient to gravitationally mobilize the sediment. The bridge may have a natural explanation if the dendrites grew by aggregation of dark material by migrating from one side of the dendrite to the other after the fault displaced them. 


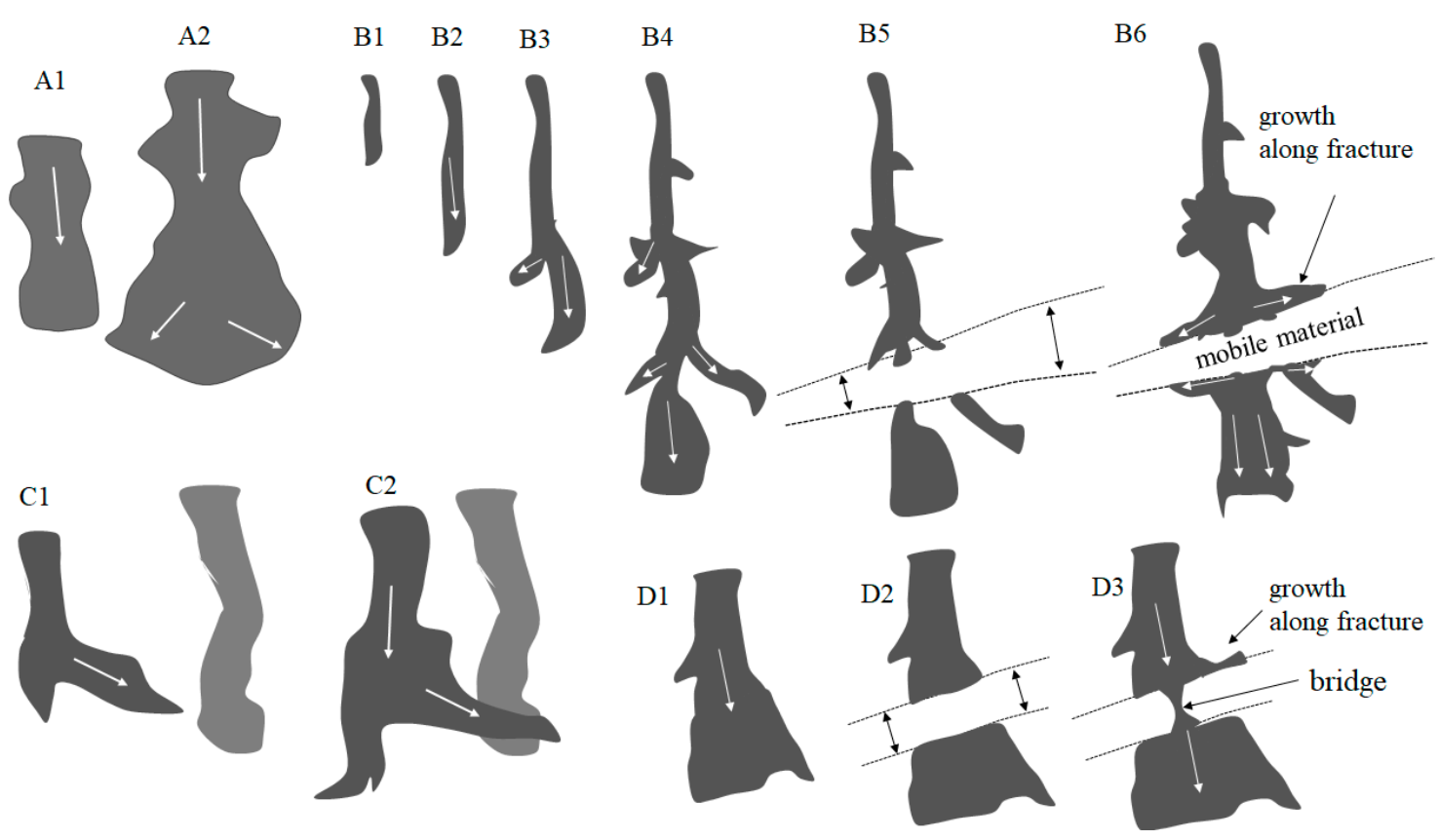

Figure 16. The four suggested patterns as deduced from images that indicate dendritic growth from the stem to the branches. (A1,A2) Dendrite increasing width as it grows. (B1-B4) Growth interrupted by sub-parallel faults, gap filled with mobile material, and subsequent growth of a narrow bridge between the two earlier connected portions (B5), dendrites growing again following the fracture lines (B6). (C1,C2) Branch superposition. (D1-D3) Faults splitting one dendrite, with the gap becoming filled with mobile material.

\subsection{Similarity to Diffusion-Controlled Aggregation in Mineral Growth}

Previously, it was shown that dendritic patterns observed in Antoniadi may be more difficult to interpret on the basis of fluvial or sapping processes and that they can better be explained by aggregation. It is interesting to emphasize that river networks are not the only systems exhibiting a dendritic shape. Dendrites are actually quite widespread in nature and may appear as the final result of many biological and nonbiological processes that occur by aggregation of building blocks onto a growing surface [83]. Figure 17 shows the familiar example of dendrites growing during the crystallization of oxides, in this case of manganese and iron, percolating at the interface between limestone layers. Typically, growth is limited by the amount of oxides available [84]. Despite the difference in scale, there are geometrical similarities between these dendrites and those in the Antoniadi crater, notably the average increase in width after the branching point, the mutual avoidance of different branches, and the tendency to grow along fractures in the limestone, where present, which act as a local reservoir of oxides.

Although unrelated to Antoniadi dendrites, this illustration of nonbiological dendrites growing via diffusion-limited aggregation is useful as a reminder that (i) not all dendrites observed in nature arise from water flow processes, and (ii) aggregation at the surface is, in principle, a scale-independent process and therefore can produce a similar pattern on different scales. The growth of stromatolite reefs in an undisturbed environment occurs as a result of aggregation of rock particles at the periphery of the growing structure onto a sticky mat [68]. Thus, as a first approximation, it may be compared to a diffusion-controlled process [85] in which colonies proliferate through propagules not only vertically but also horizontally. 


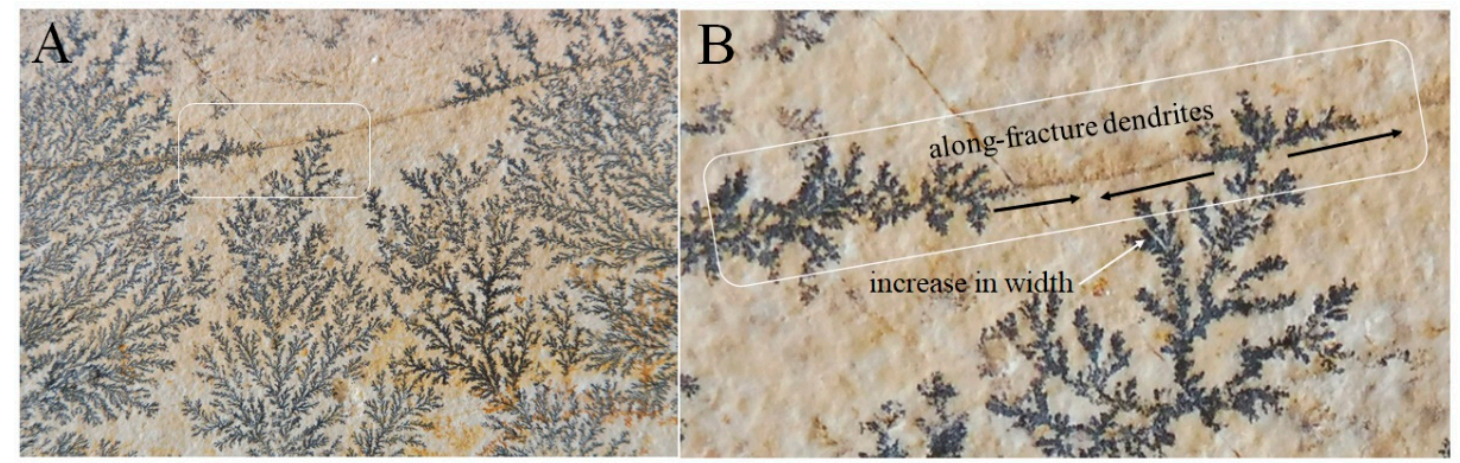

Figure 17. (A) Dendritic morphologies in a slab of Solnhofen lithographic limestone created by the action of oxides of iron and manganese. Image width of slab is $8 \mathrm{~cm}$. The white rectangle shows the area detailed in (B). (B) Enhanced growth along fracture lines in the limestone and width increase of dendrites are apparent.

\subsection{Numerical Simulations}

To better understand the possible development of dendrites in Antoniadi, it can be interesting to introduce a numerical code simulating diffusion-limited aggregation (DLA) similar to those proposed by [86] and further explored with different variants by others (e.g., $[83,87])$. In the present version of the DLA numerical code, three linear points serve as initial "seeds" for further growth of the dendrites. These points represent the first crystallized particles of the structure, and as such they are referred to as type " $\mathrm{C}$ " points. The simulation runs as follows. After fixing the initial " $\mathrm{C}$ " point particles, a large number of mobile point particles " $\mathrm{M}$ " (typically in the thousands) are let to drift with Brownian motion on the simulation area with a given diffusion coefficient, whose numerical value is of little interest for the discussion. When a mobile particle " $\mathrm{M}$ ", during its tortuous path, approaches one of the points " $\mathrm{C}$ " within a certain distance $\delta$, the point particle "freezes", becoming itself part of the structure in the place where the proximity criterion is satisfied for the first time. In practice, the counter denotes the transformation of the point of type " $\mathrm{M}$ " into a " $\mathrm{C}$ ", the particle ceases its Brownian motion, and the crystal has grown by one unit. Contrary to the classic version of DLA simulations, in which the simulation area and the distribution of the " $\mathrm{M}$ " particles is homogeneous, in this version, some selected areas have a higher density of aggregating " $\mathrm{M}$ " particles and, to simulate the presence of a barrier, the Brownian movement can be hindered perpendicular to a designed line.

Figure 18 shows the results of the simulations. The results of Figure 18A are obtained by allowing a 10-times-higher concentration of the Brownian particles in the center of the area highlighted with the rectangle. A1-A3 (Figure 18) show the evolution over time in three different stages of development, starting from the three initial points. Note first the formation of self and mutually avoiding dendrites, in strong analogy with both the oxides of Figure 17 (which is not surprising as these algorithms have been developed to reproduce such DLA crystal growing), and also compared to the dendrites in Antoniadi. Moreover, this simulation reproduces reasonably well the scheme leading to the final geometry described in Figures 2A and 6A where, according to this work, north- and southpointing units branch off from a central area. To simulate the effect of single fractures, Figure 18B shows a sequence in which the growing dendrite meets a barrier, simulated by preventing Brownian movement perpendicular to the barrier. Note the subsequent growth parallel to the barrier, in analogy with the Antoniadi dendrites growth parallel to the fractures when the supply of aggregating particles cannot cross the faults (compare with Figures 11 and 12). In short, simulations of surface-aggregating Brownian particles (DLA model) with suitable variants may provide a visual scheme for the growth of the Antoniadi dendrites as the aggregation of rock particles on the surface. Even though the modeling cannot exclude in any way that the dendrites in Antoniadi are the result of river networks, it suggests the alternate view that they may have grown from a central source unit. Being 
independent of any gravitational process, this growth mode can occur independently of the slope, and would therefore explain the counter-slope orientation of the southern unit in the central Antoniadi. Note also that the resulting profile is also compatible with growth along the fractures of the DLA crystallization systems (Figure 17).
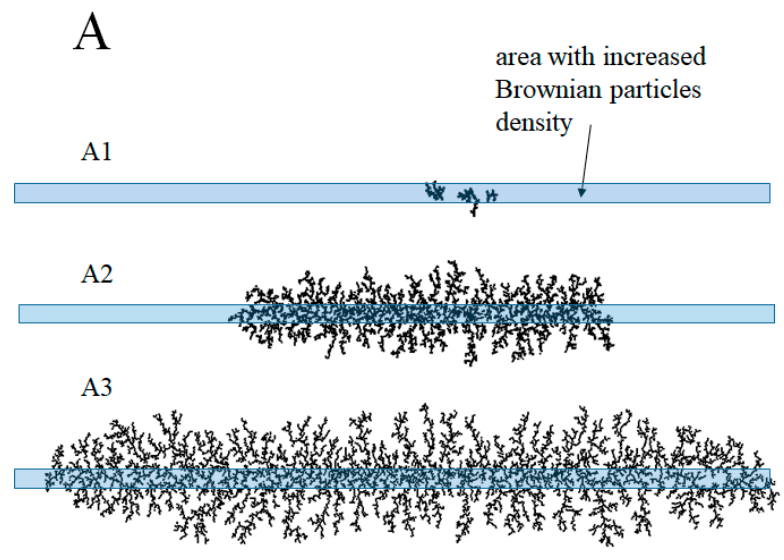

B

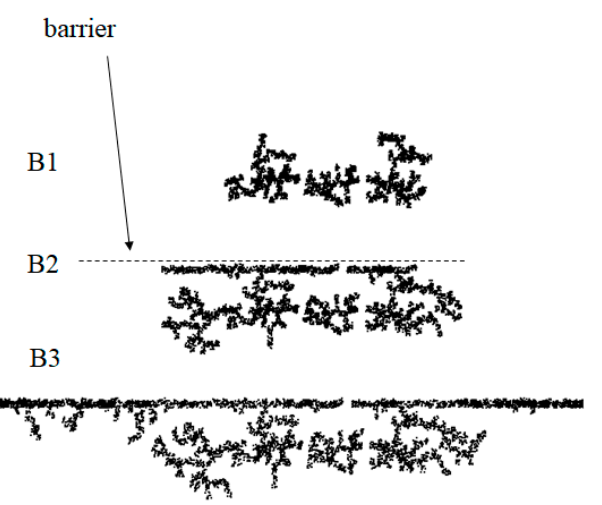

Figure 18. Simulation with DLA model. (A) The marked rectangular area has ten-fold density of Brownian particles compared to the rest of the area (time increases from A1 to A3). (B) Simulation with a barrier which mimics the presence of a fault. Time increases from B1 to B3.

\section{Discussion}

\subsection{The Privileged Condition in the Interior of the Antoniadi Crater}

The aqueous characteristics observed on Mars implying running and standing water indicate a global-scale atmospheric pressure higher than today [6]. However, this may not be enough for life, which requires water in a liquid state for geological times and therefore at much higher temperatures than today [27]. It should be noted that microbes can develop in terrestrial lakes even under unfavorable conditions in terms of temperature and salinity [66]. In fact, microbialites are not necessarily associated with warm conditions, but they also thrive in Antarctic lakes as long as the temperatures at the lake bottom are at least above freezing [88]. Microbialites can even tolerate a short period of extreme dryness [89]. The image of warm and humid Mars hypothesized to explain some aqueous morphologies [90] is gaining ground in the light of the new explorations. However, only slightly milder conditions, not only in terms of humidity and pressure, but also of temperature (supported in the past by a higher internal heat flow), may not be sufficient for a long water life and possibly for life. For this reason, it can be expected that life, if ever existed in ancient Martian lakes, would have been strongly favored within lakes heated by a local source [91]. The heat produced by the impacts of even large meteoroids is ephemeral [92]. Although the presence of plutons is not necessarily excluded within the Martian lithosphere [93-95], there are only scant local indications for plutonic activity on Mars. Therefore, only the flanks of volcanoes can be considered as an effective and long-lasting heat source for volcanic lakes. Antoniadi is located northwest of one of the great Martian volcanoes, Syrtis Mayor, which, based on the age of its main caldera Meroe Patera, was probably active around 3.5-3.73 Ga [96]. Antoniadi was engraved on the sides of this large shield formed by long lava flows, and, consequently, the temperature at its bottom could have been strongly influenced by an active or even quiescent Syrtis Major. In particular, hydrated silica deposits were found in Nili Patera, one of the calderas of Syrtis Major [97].

The age determined in Figure 5 is comparable to that of Syrtis Major's volcanic edifice, which indicates a volcano still active when the Antoniadi crater was formed and provides strong support for the hypothesis of a heated lake. In short, it is reasonable to expect that after 3.6-3.7 Ga the temperature of Lake Antoniadi was suitable for hosting microbial life. 


\subsection{Microbialites and Stromatolites on Earth and Mars}

The possibility that microbes and stromatolites may have colonized ancient Martian lakes has been advanced earlier based on the spectral response (e.g., [98]) and images of rovers $[99,100]$. There have been fewer attempts to identify biosignatures on the basis of the morphology seen by satellite images. Some authors, such as [101,102], have suggested stromatolites as a logical hypothesis for Noachian and Hesperian Mars. A first interpretation of a Martian macromorphology as a stromatolitic coral reef was made in [63], focusing on a peculiar formation inside the Pollack crater, a crater near Schiaparelli in Margaritifer Terra (Figure 19B,C). Pollack has also been the subject of a previous study suggesting its lacustrine nature [103]. This well-known structure has been nicknamed "white rock" due to its high thermal inertia, which makes it appear luminous in nighttime infrared images, a feature which is also displayed by the dendrites in Antoniadi (Figure 2B,C). Based on morphological similarities, biochemical indications, and using Viking images, Russell et al. [63] found significant correspondences between the Pollack feature and the microbial structures of Lake Salda in Turkey, where hydromagnesite stromatolites abound (Figure 19A). More recently, HiRISE has provided several high-resolution optical images of Pollack showing that the "reef" appears to be composed of lattice subunits, each approximately 2-3 $\mathrm{m}$ in diameter (Figure 19C). Some of the morphological characteristics of the structures of the Antoniadi crater are exhibited by certain terrestrial biogenic reefs. For example, the algal mats in Laguna Mormona (Baja California, Mexico) that form in the evaporitic flats of desiccant lagoons grow in subunits about half a meter in diameter [104]. Figure 19D shows some of the best known living stromatolites in the Shark Bay in Western Australia. Note the branching patterns of stromatolite assemblages highlighted with arrows. Not surprisingly, they are limited to the shore and low depth. The constant lake depth in Antoniadi, which is evidently typical of the bottom of lakes in impact craters, may have favored a longer spread of microbialites in Antoniadi.
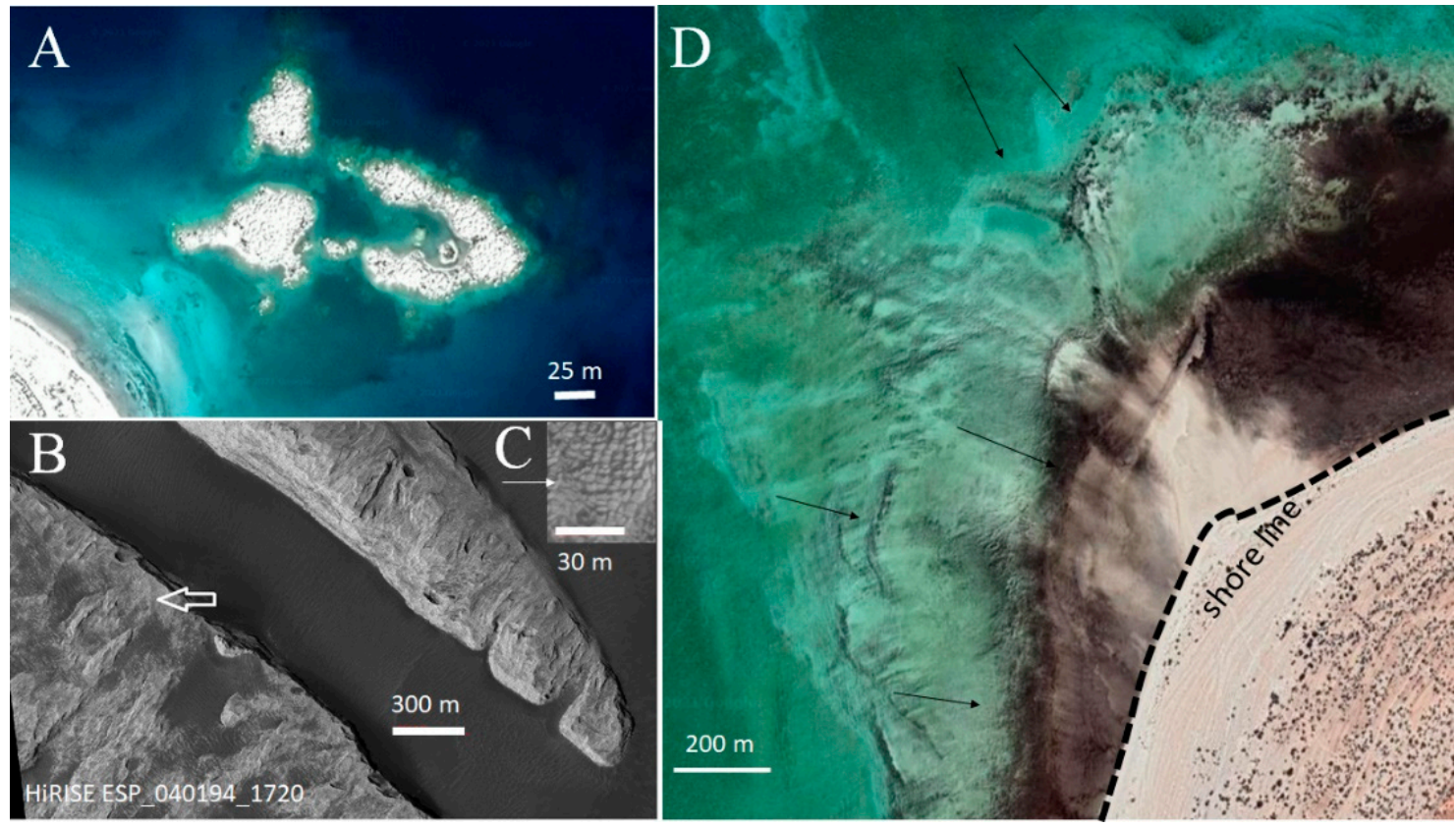

Figure 19. (A) Stromatolites in Lake Salda, Turkey. Image courtesy of Google Earth. (B) The "white rock" inside crater Pollack, Mars. HiRISE image. (C) Detail of the area in (B) indicated with an arrow. (D) Stromatolites in Shark Bay. Image courtesy of Google Earth.

One conceivable criticism to the possible biological origin of the dendrites in Antoniadi is that it would require the concomitant origin of life on the Earth and Mars, which is unlikely. However, according to the theory of lithopanspermia, and as discussed in 
Appendix A, the exchange of rock fragments between the Earth and Mars after energetic meteoroid impacts is a process which may have traded life-bearing particles between the two planets.

The oldest stromatolitic rocks on Earth are about $3.7 \mathrm{Ga}$ in age [105], close to the same age as the Antoniadi lake fill and corresponding to the beginning of the Hesperian period. In short, it is not impossible that in a period when air pressure and humidity were much higher than today (e.g., $[6,106,107])$ and water, essential for life $[2,4,108]$, was commonplace [6-8], the presence of stromatolitic life on Mars, perhaps carried by Earth, was thriving. The rovers documented that the areas of the Meridian Planum and Gusev, Gale, and Jezero craters were rich in water during and at the end of the Hesperian period, or 3.7 Ga. As geological investigations on our planet have shown, past lakes may be one of the most favorable environments for ancient stromatolite life on Mars [109], and, perhaps, their bottoms may have even preserved life [4].

\section{Conclusions}

The crater Antoniadi has enjoyed peculiar conditions throughout the history of Mars, as it has experienced the following situations favorable to life: (i) it formed early when the planet was warmer, and atmospheric pressures were probably much higher than today; (ii) as liquid water was still abundant on the planet, many impact craters were filled by water to form a lake, and in the scenario suggested here, Antoniadi was no exception; (iii) The large size of Antoniadi may have played a significant role in the sequestration of water, climatic stability, and the maintenance of a warm lake; (iv) its proximity to the dichotomous boundary where an ocean was probably present could have favored the abundance of water compared to a crater of the same age in the southern highlands; (v) Antoniadi was close to the important volcanic system of Syrtis Major, whose magmatic activity likely kept the waters of the alleged lake warm for a geologically significant time; (vi) the low albedo soil typical of the Syrtis Major area, a characteristic noticed already by early observers, could have been a further advantage in capturing the solar heat.

The paper has documented a number of dark dendritic structures within this crater distributed in three small central areas. Such dendrites, of tens of kilometers in size, are geometrically arranged in a stem-like unit developing in numerous branches. It has been suggested that the dendrites grew from stem to branches, and, therefore, it may be problematic to interpret them as remnants of inverted river network or sapping groundwater channels. The interpretation as alluvial fans or deltas, although correct in terms of pattern polarity, may be difficult as well, owing to the lack of the numerous braided channels. Furthermore, the area with dendrites currently has a gentle slope incompatible with river processes, and even of incorrect polarity in some areas of the central dendrites.

Several puzzling features visible at high resolution (see Appendix B for details on data sources), such as growth parallel to fault lines and bridges between separated branches, have been discussed, which apparently strengthen the hypothesis that the dendrites grew by aggregation on their edges. Considering that life on Mars, if it ever existed, was more likely in the form of reef-building structures such as microbial reefs and stromatolites (which bear a strong resemblance to dendrites from tens of meters to kilometers), it is suggested that Antoniadi may have been colonized by microbialite life arranged in gigantic tabular units. Although the data presented in this article are based on morphological analyses and similarities to terrestrial stromatolites, it is worth examining further whether such dendrites are biogenic. The presumed reef of Antoniadi would apparently have the same age as the crater interior deposits, or about 3.8-3.9 Ga, corresponding to the late Noachian. The data indicate a climate shift from wet to arid Mars that probably occurred much later, or around 3.5-3 Ga, in the mid-Hesperian and early Amazonian, when life within the crater, if it ever existed, may have become extinct. Evidently, although the peculiar geometry and morphologies of the dendrites in Antoniadi as described in this work cannot in any way constitute evidence of the presence of microbialites in ancient Mars, their puzzling nature requires further investigation. 
To summarize, the particular dendrites within the Antoniadi crater could stand out as an exciting place for future surface lander missions with astrobiology-related aims [110,111].

Funding: This research received no external funding.

Data Availability Statement: All data and images can be retrieved from the references and internet pages indicated in the paper; for further data on the numerical simulation please contact the author.

Acknowledgments: I thank Vincenzo Rizzo for the numerous informative discussions on the possibility of Martian stromatolites and Biagio Di Mauro for exchange of ideas on the concept of lithopanspermia. The referee Toby Samuels and another anonymous reviewer substantially improved the quality of the paper through numerous important comments.

Conflicts of Interest: The author declares no conflict of interest.

\section{Appendix A. Transfer of Rocky Material between Earth and Mars}

According to the lithopanspermia theory, asteroid impacts can eject rock from planetary surfaces, causing the exchange of life-bearing rocks between different planets and moons of the solar system [112]. Furthermore, impacts can also redistribute the material within the surface of the same planet. Therefore, considering the provenance of different classes of meteorites from Mars [113], it is conceivable that the reverse journey may also have taken place and that the surface of Mars may have been contaminated by terrestrial life due to impacts on our planet in the Archean. Although the escape velocity from Earth is more than twice that from Mars, it should be considered that asteroid impacts on Earth release, on average, much more energy per unit mass owing to the higher impact velocity (the average asteroid impact velocity is $13.6 \mathrm{~km} / \mathrm{s}$ versus $17.6 \mathrm{~km} / \mathrm{s}$ for Mars and Earth, respectively [114]). Thus, the hindrance to rock expulsion into space due to the greater gravity field on our planet is partly compensated by the higher speed of the impactor and the resulting ejecta. Altogether, calculations indicate that the effect of the escape velocity prevails. In particular, the probability that rock expelled from Earth by asteroid impact may reach Mars is 50 times lower than the probability of Martian rocks taking the opposite journey, a large but not dramatic difference [114].

\section{Appendix B. Data Sources}

A first set of images used in this work were taken by the Context CTX optical camera on board the Mars Reconnaissance Orbiter, with a resolution typically of $6 \mathrm{~m}$ per pixel [115]. Infrared images from Thermal Emission Imaging System (THEMIS) on board the Mars Odyssey mission have a resolution of $100 \mathrm{~m}$ per pixel [40]. High Resolution Imaging Science Experiment (HiRISE) images on board the Mars Reconnaissance Orbiter of high resolution, with average resolution of $25-30 \mathrm{~cm}$ per pixel, were of fundamental importance for the examination of the smallest features, as they cover the most interesting portion of the Antoniadi crater [116]. A digital terrain model (DTM) based on HiRISE stereo pairs produced by the University of Arizona Lunar and Planetary Laboratory was also used. The Mars Orbiter Laser Altimeter (MOLA) aboard the Mars Global Surveyor mission (MGS [117]) provided both hillshade images and coarse topographic sections. The Java Mission-planning and Analysis for Remote Sensing (JMARS) platform provided and updated by Arizona State University has been widely used. For the dating of the soils, the diameters of the craters were measured on optical CTX images, using the Craterstats software package [40,42], and compared with the theoretical statistical predictions based on the cumulative frequency functions of Neukum and on the production function of Ivanov [118].

\section{References}

1. Kereszturi, A.; Petrik, A. Age determination for valley networks on Mars using tectonic-fluvial interaction. Planet. Space Sci. 2020, 180, 104754. [CrossRef]

2. Irwin, L.N.; Schulze-Makuch, D. The astrobiology of alien worlds: Known and unknown forms of life. Universe 2020, 6, 130. [CrossRef] 
3. Orosei, R.; Ding, C.; Fa, W.; Giannopoulos, A.; Hérique, A.; Kofman, W.; Lauro, S.E.; Li, C.; Pettinelli, E.; Su, Y.; et al. The Global Search for Liquid Water on Mars from Orbit: Current and Future Perspectives. Life 2020, 10, 120. [CrossRef]

4. Tarnas, J.D.; Mustard, J.F.; Sherwood Lollar, B.; Stamenković, V.; Cannon, K.M.; Lorand, J.P.; Onstott, T.C.; Michalski, J.R.; Warr O.; Palumbo, A.M.; et al. Earth-like Habitable Environments in the Subsurface of Mars. Astrobiology 2021, 21, 741-756. [CrossRef] [PubMed]

5. Baker, V.R.; Strom, R.G.; Gulick, V.C.; Kargel, J.S.; Komatsu, G.; Kale, V.S. Ancient oceans, ice sheets and the hydrological cycle on Mars. Nature 1991, 352, 589-594. [CrossRef]

6. Carr, M.H. Water on Mars; Oxford University Press: New York, NY, USA, 1996.

7. Baker, V. Water and the Martian landscape. Nature 2001, 412, 228-236. [CrossRef]

8. Carr, M.H.; Head, J.W., III. Oceans on Mars: An assessment of the observational evidence and possible fate. J. Geophys. Res. Planets 2003, 108. [CrossRef]

9. Hynek, B.M.; Beach, M.; Hoke, M.R. Updated global map of Martian valley networks and implications for climate and hydrologic processes. J. Geophys. Res. Planets 2010, 115. [CrossRef]

10. Luo, W.; Cang, X.; Howard, A.D. New Martian valley network volume estimate consistent with ancient ocean and warm and wet climate. Nat. Commun. 2017, 8, 1-7. [CrossRef]

11. Parker, T.J.; Gorsline, D.S.; Saunders, R.S.; Pieri, D.C.; Schneeberger, D.M. Coastal geomorphology of the Martian northern plains J. Geophys. Res. Planets 1993, 98, 11061-11078. [CrossRef]

12. Parker, T.J.; Grant, J.A.; Franklin, B.J. The northern plain: A Martian oceanic basin? In Lakes on Mars; Cabrol, N.A., Grin, E.A., Eds.; Elsevier: Amsterdam, The Netherlands, 2010.

13. Bishop, J.L. Remote detection of phyllosilicates on Mars and implications for climate and habitability. In From Habitability to Life on Mars; Elsevier: Amsterdam, The Netherlands, 2018; pp. 37-75.

14. Lucchitta, B.K.; McEwen, A.S.; Clow, G.D.; Geissler, P.E.; Singer, R.B.; Schultz, R.A.; Squyres, S.W. The Canyon System on Mars; Mars, Kieffer, H.H., Eds.; University of Arizona Press: Tucson, AZ, USA, 1992; pp. 453-492.

15. Di Achille, G.; Hynek, B.M. Ancient ocean on Mars supported by global distribution of deltas and valleys. Nat. Geosci. 2010, 3 , 459-463. [CrossRef]

16. DiBiase, R.A.; Limaye, A.B.; Scheingross, J.S.; Fischer, W.W.; Lamb, M.P. Deltaic deposits at Aeolis Dorsa: Sedimentary evidence for a standing body of water on the northern plains of Mars. J. Geophys. Res. Planets 2013, 118, 1285-1302. [CrossRef]

17. Goudge, T.A.; Milliken, R.E.; Head, J.W.; Mustard, J.F.; Fassett, C.I. Sedimentological evidence for a deltaic origin of the western fan deposit in Jezero crater, Mars and implications for future exploration. Earth Planet. Sci. Lett. 2017, 458, 357-365. [CrossRef]

18. De Blasio, F.V. Possible erosion marks of bottom oceanic currents in the northern lowlands of Mars. Planet. Space Sci. 2014, 93, 10-21. [CrossRef]

19. Moscardelli, L. Boulders of the Vastitas Borealis Formation: Potential origin and implications for an ancient martian ocean. GSA Today 2014, 24, 4-10. [CrossRef]

20. Rodriguez, J.A.P.; Fairén, A.G.; Tanaka, K.L.; Zarroca, M.; Linares, R.; Platz, T.; Komatsu, G.; Miyamoto, H.; Kargel, J.S.; Yan, J.; et al. Tsunami waves extensively resurfaced the shorelines of an early Martian ocean. Sci. Rep. 2016, 6, 1-8. [CrossRef]

21. De Blasio, F.V. Frontal Aureole Deposit on Acheron Fossae ridge as evidence for landslide-generated tsunami on Mars. Planet. Space Sci. 2020, 187, 104911. [CrossRef]

22. Wharton, R.A.; Crosby, J.M.; McKay, C.P.; Rice, J.W. Paleolakes on Mars. J. Paleolimnol. 1995, 13, 267-283. [CrossRef]

23. De Hon, R.A. Hydrologic provinces of Mars: Physiographic controls on drainage and ponding. In Lakes on Mars; Elsevier: Amsterdam, The Netherlands, 2010; pp. 68-89.

24. Lucchitta, B.K. Lakes in Valles Marineris. In Lakes on Mars; Elsevier: Amsterdam, The Netherlands, $2010 ;$ pp. 111-161.

25. Harrison, K.P.; Chapman, M.G. Evidence for ponding and catastrophic floods in central Valles Marineris, Mars. Icarus 2008, 198, 351-364. [CrossRef]

26. Cabrol, N.A.; Grin, E.A. Searching for lakes on Mars: Four decades of exploration. In Lakes on Mars; Elsevier: Amsterdam, The Netherlands, 2010; pp. 1-29.

27. Newsom, H.E.; Brittelle, G.E.; Hibbitts, C.A.; Crossey, L.J.; Kudo, A.M. Impact crater lakes on Mars. J. Geophys. Res. Planets 1996, 101, 14951-14955. [CrossRef]

28. Arvidson, R.E.; Catalano, J.G. Martian Habitability as Inferred From Landed Mission Observations. In From Habitability to Life on Mars; Elsevier: Amsterdam, The Netherlands, 2018; pp. 77-126.

29. Ori, G.G.; Marinangeli, L.; Baliva, A. Terraces and Gilbert-type deltas in crater lakes in Ismenius Lacus and Memnonia (Mars). J. Geophys. Res. Planets 2000, 105, 17629-17641. [CrossRef]

30. Flannery, D.T.; Summons, R.E.; Walter, M.R. Archean Lakes as analogues for habitable Martian paleoenvironments. In From Habitability to Life on Mars; Elsevier: Amsterdam, The Netherlands, 2018; pp. 127-152.

31. Smith, M.R.; Bandfield, J.L.; Gillespie, A.R. Felsic and altered mineral suite in Antoniadi Crater, Mars as a future rover landing site. In Proceedings of the 42nd Lunar and Planetary Science Conference, Woodlands, TX, USA, 7-11 March 2011 ; p. 1671.

32. Smith, M.R.; Bandfield, J.L. Geology of quartz and hydrated silica-bearing deposits near Antoniadi Crater, Mars. J. Geophys. Res. Planets 2012, 117. [CrossRef]

33. Garvin, J.B.; Sakimoto, S.E.H.; Frawley, J.J. Craters on Mars: Global geometric properties from gridded MOLA. In Proceedings of the Sixth International Conference on Mars, Pasadena, CA, USA, 20-25 July 2003; Volume 3. 
34. Zegers, T.E.; Oosthoek, J.H.; Rossi, A.P.; Blom, J.K.; Schumacher, S. Melt and collapse of buried water ice: An alternative hypothesis for the formation of chaotic terrains on Mars. Earth Planet. Sci. Lett. 2010, 297, 496-504. [CrossRef]

35. McEwen, A. Branched Features on the Floor of Antoniadi Crater. 2009. Available online: https://www.uahirise.org/ESP_012435 2015 (accessed on 31 July 2020).

36. Zaki, A.S.; Pain, C.F.; Edgett, K.S.; Giegengack, R. Inverted stream channels in the Western Desert of Egypt: Synergistic remote, field observations and laboratory analysis on Earth with applications to Mars. Icarus 2018, 309, 105-124. [CrossRef]

37. Brooker, L.M.; Balme, M.R.; Conway, S.J.; Hagermann, A.; Barrett, A.M.; Collins, G.S.; Soare, R.J. Clastic polygonal networks around Lyot crater, Mars: Possible formation mechanisms from morphometric analysis. Icarus 2018, 302, 386-406. [CrossRef]

38. Harris, R.C. Giant Desiccation Cracks in Arizona; Arizona Geological Survey: Tucson, AZ, USA, 2004; 93p.

39. El-Maarry, M.R.; Watters, W.; McKeown, N.K.; Carter, J.; Dobrea, E.N.; Bishop, J.L.; Pommerol, A.; Thomas, N. Potential desiccation cracks on Mars: A synthesis from modeling, analogue-field studies, and global observations. Icarus 2014, 241, 248-268. [CrossRef]

40. Michael, G.G. Planetary surface dating from crater size-frequency distribution measurements: Multiple resurfacing episodes and differential isochron fitting. Icarus 2013, 226, 885-890. [CrossRef]

41. Christensen, P.R.; Jakosky, B.M.; Kieffer, H.H.; Malin, M.C.; McSween, H.Y.; Nealson, K.; Mehall, G.L.; Silverman, S.H.; Ferry, S.; Caplinger, M.; et al. The thermal emission imaging system (THEMIS) for the Mars 2001 Odyssey Mission. Space Sci. Rev. 2004, 110, 85-130. [CrossRef]

42. Michael, G.G.; Neukum, G. Planetary surface dating from crater size-frequency distribution measurements: Partial resurfacing events and statistical age uncertainty. Earth Planet. Sci. Lett. 2010, 294, 223-229. [CrossRef]

43. Tanaka, K.L.; Skinner, J.A., Jr.; Dohm, J.M.; Irwin, R.P., III; Kolb, E.J.; Fortezzo, C.M.; Platz, T.; Michael, G.G.; Hare, T.M. Geologic Map of Mars; USGS: Reston, VA, USA, 2014.

44. Soare, R.J.; Burr, D.M.; Tseung, J.M.W.B. Possible pingos and a periglacial landscape in northwest Utopia Planitia. Icarus 2005, 174, 373-382. [CrossRef]

45. Orgel, C.; Hauber, E.; van Gasselt, S.; Reiss, D.; Johnsson, A.; Ramsdale, J.D.; Smith, I.; Swirad, Z.M.; Séjourné, A.; Wilson, J.T.; et al. Grid mapping the northern plains of Mars: A new overview of recent water-and ice-related landforms in Acidalia Planitia. J. Geophys. Res. Planets 2019, 124, 454-482. [CrossRef]

46. Séjourné, A.; Costard, F.; Swirad, Z.M.; Łosiak, A.; Bouley, S.; Smith, I.; Balme, M.R.; Orgel, C.; Ramsdale, J.D.; Hauber, E.; et al Grid mapping the northern plains of Mars: Using morphotype and distribution of ice-related landforms to understand multiple ice-rich deposits in Utopia Planitia. J. Geophys. Res. Planets 2019, 124, 483-503. [CrossRef]

47. Mellon, M.T.; Arvidson, R.E.; Marlow, J.J.; Phillips, R.J.; Asphaug, E. Periglacial landforms at the Phoenix landing site and the northern plains of Mars. J. Geophys. Res. Planets 2008, 113. [CrossRef]

48. El Maarry, M.R.; Markiewicz, W.J.; Mellon, M.T.; Goetz, W.; Dohm, J.M.; Pack, A. Crater floor polygons: Desiccation patterns of ancient lakes on Mars? J. Geophys. Res. Planets 2010, 115. [CrossRef]

49. Chan, M.A.; Nicoll, K.; Ormö, J.; Okubo, C.; Komatsu, G. Utah's geologic and geomorphic analogs to Mars-An overview for planetary exploration. Geol. Soc. Am. Spec. Pap. 2011, 483, 349-375.

50. Pain, C.F.; Clarke, J.D.A.; Thomas, M. Inversion of relief on Mars. Icarus 2007, 190, 478-491. [CrossRef]

51. Mangold, N.; Quantin, C.; Ansan, V.; Delacourt, C.; Allemand, P. Evidence for precipitation on Mars from dendritic valleys in the Valles Marineris area. Science 2004, 305, 78-81. [CrossRef]

52. Burr, D.M.; Williams, R.M.; Wendell, K.D.; Chojnacki, M.; Emery, J.P. Inverted fluvial features in the Aeolis/Zephyria Plana region, Mars: Formation mechanism and initial paleodischarge estimates. J. Geophys. Res. Planets 2010, 115. [CrossRef]

53. Leopold, L.B.; Wolman, M.G.; Miller, J.P. Fluvial Processes in Geomorphology; Courier Dover Publications: Mineola, NY, USA, 2020.

54. Isherwood, R.J.; Jozwiak, L.M.; Jansen, J.C.; Andrews-Hanna, J.C. The volcanic history of Olympus Mons from paleo-topography and flexural modeling. Earth Planet. Sci. Lett. 2013, 363, 88-96. [CrossRef]

55. Lefort, A.; Burr, D.M.; Nimmo, F.; Jacobsen, R.E. Channel slope reversal near the Martian dichotomy boundary: Testing tectonic hypotheses. Geomorphology 2015, 240, 121-136. [CrossRef]

56. Banerdt, W.B.; Golombek, M.P.; Tanaka, K.L. Stress and tectonics on Mars. Mars 1992, 249-297.

57. Golombek, M.P.; Phillips, R.J. Mars tectonics. In Planetary Tectonics; Watters, T.R., Schultz, R.A., Eds.; Cambridge University Press: Cambridge, UK, 2010; pp. 183-232.

58. Kah, L.C.; Bartley, J.K.; Stagner, A.F. Reinterpreting a proterozoic enigma: Conophyton-Jacutophyton stromatolites of the Mesoproterozoic Atar group, Mauritania. Int. Assoc. Sediment. Spec. Pub. 2009, 41, 277-295.

59. Noffke, N. Geobiology: Microbial Mats in Sandy Deposits from the Archean Era to Today; Springer Science and Business Media: Berlin, Germany, 2010

60. Reitner, J.; Quéric, N.-V.; Arp, G. Advances in Stromatolite Geobiology; Springer: Heidelberg, Germany, 2011; 559p.

61. Riding, R. Microbialites, stromatolites, and thrombolites. In Encyclopedia of Geobiology, Encyclopedia of Earth Sciences Series; Reitner, J., Thiel, V., Eds.; Springer Netherlands: Dordrecht, The Netherlands, 2011; pp. 635-654.

62. Bosak, T.; Knoll, A.H.; Petroff, A.P. The meaning of stromatolites. Annu. Rev. Earth Planet. Sci. 2013, 41, 21-44. [CrossRef]

63. Russell, M.J.; Ingham, J.K.; Zedef, V.; Maktav, D.; Sunar, F.; Hall, A.J.; Fallick, A.E. Search for signs of ancient life on Mars: Expectations from hydromagnesite microbialites, Salda Lake, Turkey. J. Geol. Soc. 1999, 156, 869-888. [CrossRef] 
64. Noffke, N. Ancient sedimentary structures in the $<3.7 \mathrm{~b}$ Ga Gillespie Lake Member, Mars, that Compare in macroscopic morphology, spatial associations, and temporal succession with terrestrrial microbialites. Astrobiology 2015, 15, 169-192. [CrossRef]

65. Cady, S.L.; Skok, J.R.; Gulick, V.G.; Berger, J.A.; Hinman, N.W. Siliceous hot spring deposits: Why they remain key astrobiological targets. In From Habitability to Life on Mars; Elsevier: Amsterdam, The Netherlands, 2018; pp. 179-210.

66. Talbot, M.R.; Allen, P.A. Lakes. In Sedimentary Environments: Processes, Facies and Stratigraphy; Reading, H.G., Ed.; John Wiley \& Sons: Hoboken, NJ, USA, 1996; pp. 83-124.

67. Cockell, C.S.; Lee, P. The biology of impact craters-A review. Biol. Rev. 2002, 77, 279-310. [CrossRef]

68. Altermann, W. Accretion, trapping and binding of sediment in Archean stromatolites morphological expression of the antiquity of life. Space Sci. Rev. 2008, 135, 55-79. [CrossRef]

69. Awramik, S.M.; Buchheim, H.P. Giant stromatolites of the Eocene Green River Formation (Colorado, USA). Geology 2015, 43, 691-694. [CrossRef]

70. Andres, M.S.; Reid, R.P. Growth morphologies of modern marine stromatolites: A case study from Highborne Cay, Bahamas Sediment. Geol. 2006, 185, 319-328. [CrossRef]

71. Ricketts, B.D.; Donaldson, J.A. Stromatolite Reef Development on a Mud-Dominated Platform in the Middle Precambrian Belcher Group of Hudson Bay; AAPG: Tulsa, OK, USA, 1988.

72. Bridge, J.; Demicco, R. Earth Surface Processes, Landforms and Sediment Deposits; Cambridge University Press: Cambridge, UK, 2008.

73. Peters, S.E.; Husson, J.M.; Wilcots, J. The rise and fall of stromatolites in shallow marine environments. Geology 2017, 45, 487-490. [CrossRef]

74. Horgan, B.H.; Anderson, R.B.; Dromart, G.; Amador, E.S.; Rice, M.S. The mineral diversity of Jezero crater: Evidence for possible lacustrine carbonates on Mars. Icarus 2019, 339, 113526. [CrossRef]

75. Grotzinger, J.P.; Knoll, A.H. Stromatolites in Precambrian carbonates: Evolutionary mileposts or environmental dipsticks? Annu. Rev. Earth Planet. Sci. 1999, 27, 313-358. [CrossRef] [PubMed]

76. Grey, K.; Planavsky, N.J. Microbialites of Lake Thetis, Cervantes, Western Australia: A Field Guide; Geological Survey of Western Australia: Perth, Australia, 2009.

77. Grey, K.; Moore, L.S.; Burne, R.V.; Pierson, B.K.; Bauld, J. Lake Thetis, Western Australia: And example of saline lake sedimentation dominated by benthic microbial processes. Aust. J. Mar. Freshw. Res. 1990, 41, 275-300. [CrossRef]

78. Meltzner, A.J.; Woodroffe, C.D. Coral microatolls. In Handbook of Sea-Level Research; Wiley: Hoboken, NJ, USA, 2015; pp. 125-145.

79. Getzin, S.; Yizhaq, H.; Bell, B.; Erickson, T.E.; Postle, A.C.; Katra, I.; Tsuk, O.; Zelnik, Y.R.; Wiegand, K.; Wiegand, T.; et al. Discovery of fairy circles in Australia supports self-organization theory. Proc. Natl. Acad. Sci. USA 2016, 113, $3551-3556$. [CrossRef] [PubMed]

80. Horodyski, R.J.; Bloeser, B.; Vonder Haar, S. Laminated algal mats from a coastal lagoon, Laguna Mormona, Baja California, Mexico. J. Sediment. Res. 1977, 47, 680-696.

81. Kovalchuk, O.; Owttrim, G.W.; Konhauser, K.O.; Gingras, M.K. Desiccation cracks in siliciclastic deposits: Microbial mat-related compared to abiotic sedimentary origin. Sediment. Geol. 2017, 347, 67-78. [CrossRef]

82. Seibold, E.; Berger, W. The Sea Floor: An Introduction to Marine Geology; Springer: Berlin/Heidelberg, Germany, 2017.

83. Barabási, A.L.; Stanley, H.E. Fractal Concepts in Surface Growth; Cambridge University Press: Cambridge, UK, 1995.

84. García-Ruiz, J.M.; Otálora, F.; Sanchez-Navas, A.; Higes-Rolando, F.J. The formation of manganese dendrites as the mineral record of flow structures. In Fractals and Dynamic Systems in Geoscience; Springer: Berlin/Heidelberg, Germany, 1994; pp. 307-318.

85. Dupraz, C.; Pattisina, R.; Verrecchia, E.P. Translation of energy into morphology: Simulation of stromatolite morphospace using a stochastic model. Sediment. Geol. 2006, 185, 185-203. [CrossRef]

86. Witten, T.A., Jr.; Sander, L.M. Diffusion-limited aggregation, a kinetic critical phenomenon. Phys. Rev. Lett. 1981, $47,1400$. [CrossRef]

87. Braga, F.L.; Ribeiro, M.S. Diffusion limited aggregation: Algorithm optimization revisited. Comput. Phys. Commun. 2011, 182, 1602-1605. [CrossRef]

88. Parker, B.C.; Simmons, G.M., Jr.; Love, F.G.; Wharton, R.A., Jr.; Seaburg, K.G. Modern stromatolites in Antarctic dry valley lakes. BioScience 1981, 31, 656-661. [CrossRef]

89. Billi, D. Desert cyanobacteria under space and planetary simulations: A tool for searching for life beyond Earth and supporting human space exploration. Int. J. Astrobiol. 2019, 18, 483-489. [CrossRef]

90. Kargel, J.S. Mars-A Warmer, Wetter Planet; Springer Science and Business Media: Berlin, Germany, 2004.

91. Newsom, H.E. Heated Lakes on Mars; Elsevier: Amsterdam, The Netherlands, 2010; pp. 93-110.

92. Abramov, O.; Kring, D.A. Impact-induced hydrothermal activity on early Mars. J. Geophys. Res. Planets 2005, 110. [CrossRef]

93. Williams, J.P.; Paige, D.A.; Manning, C.E. Layering in the wall rock of Valles Marineris: Intrusive and extrusive magmatism. Geophys. Res. Lett. 2003, 30. [CrossRef]

94. Yin, A. Structural analysis of the Valles Marineris fault zone: Possible evidence for large-scale strike-slip faulting on Mars. Lithosphere 2012, 4, 286-330. [CrossRef]

95. Carter, J.; Poulet, F. Ancient plutonic processes on Mars inferred from the detection of possible anorthositic terrains. Nat. Geosci. 2013, 6, 1008-1012. [CrossRef]

96. Werner, S.C. The global martian volcanic evolutionary history. Icarus 2009, 201, 44-68. [CrossRef] 
97. Skok, J.R.; Mustard, J.F.; Ehlmann, B.L.; Milliken, R.E.; Murchie, S.L. Silica deposits in the Nili Patera caldera on the Syrtis Major volcanic complex on Mars. Nat. Geosci. 2010, 3, 838-841. [CrossRef]

98. Ruff, W.; Farmer, J.D. Silica deposits on Mars with features resembling hot spring biosignatures at El Tatio in Chile. Nat. Commun 2016, 7, 13554. [CrossRef]

99. Rizzo, V.; Cantasano, N. Possible organosedimentary structures on Mars. Int. J. Astrobiol. 2009, 8, 267-280. [CrossRef]

100. Rizzo, V. Why should geological criteria used on Earth not be valid also for Mars? Evidence of possible microbialites and algae in extinct Martian lakes. Int. J. Astrobiol. 2020, 19, 283-294. [CrossRef]

101. McKay, C.P.; Stoker, C.R. The early environment and its evolution on Mars: Implication for life. Rev. Geophys. 1989, 27, 189-214. [CrossRef]

102. Tewari, V.C. Earliest Microbes on Earth and Possible Occurrence of Stromatolites on Mars. In Exobiology: Matter, Energy, and Information in the Origin and Evolution of Life in the Universe; Chela-Flores, J., Raulin, F., Eds.; Springer: Dordrecht, The Netherlands, 1998.

103. Williams, S.H.; Zimbelman, J.R. “White Rock": An eroded Martian lacustrine deposit (?). Geology 1994, 22, 107-110. [CrossRef]

104. Horodyski, R.J. Lyngbya mats at Laguna Mormona, Baja California, Mexico; comparison with Proterozoic stromatolites. J. Sediment. Res. 1977, 47, 1305-1320.

105. Nutman, A.P.; Bennett, V.C.; Friend, C.R.; Van Kranendonk, M.J.; Chivas, A.R. Rapid emergence of life shown by discovery of 3,700-million-year-old microbial structures. Nature 2016, 537, 535-538. [CrossRef]

106. Kamada, A.; Kuroda, T.; Kasaba, Y.; Terada, N.; Nakagawa, H. Global climate and river transport simulations of early Mars around the Noachian and Hesperian boundary. Icarus 2021, 368, 114618. [CrossRef]

107. Guzewich, S.D.; Way, M.J.; Aleinov, I.; Wolf, E.T.; Del Genio, A.; Wordsworth, R.; Tsigaridis, K. 3D Simulations of the Early Martian Hydrological Cycle Mediated by a H2-CO2 Greenhouse. J. Geophys. Res. Planets 2021, 126, e2021JE006825. [CrossRef]

108. Cockell, C.S.; Bush, T.; Bryce, C.; Direito, S.; Fox-Powell, M.; Harrison, J.P.; Lammer, H.; Landenmark, H.; Martin-Torres, J.; Nicholson, N.; et al. Habitability: A review. Astrobiology 2016, 16, 89-117. [CrossRef]

109. Grotzinger, J.P.; Gupta, S.; Malin, M.C.; Rubin, D.M.; Schieber, J.; Siebach, K.; Calef, F. Deposition, exhumation, and paleoclimate of an ancient lake deposit, Gale crater, Mars. Science 2015, 350, aac7575. [CrossRef]

110. Domagal-Goldman, S.D.; Wright, K.E.; Adamala, K.; De La Rubia, L.A.; Bond, J.; Dartnell, L.R.; Goldman, A.D.; Lynch, K.; Naud, M.E.; Paulino-Lima, I.G.; et al. The astrobiology primer v2.0. Astrobiology 2016, 16, 561.

111. Kereszturi, A.; Bradák, B.; Chatzitheodoridis, E.; Ujvari, G. Indicators and methods to understand past environments from ExoMars rover drills. Orig. Life Evol. Biosph. 2016, 46, 435-454. [CrossRef] [PubMed]

112. Gladman, B. Destination: Earth. Martian meteorite delivery. Icarus 1997, 130, 228-246. [CrossRef]

113. McSween, H.Y.; McSween, H.Y.; McSween, J. Meteorites and Their Parent Planets; Cambridge University Press: Cambridge, UK, 1999.

114. Mileikowsky, C.; Cucinotta, F.A.; Wilson, J.W.; Gladman, B.; Horneck, G.; Lindegren, L.; Melosh, J.; Rickman, H.; Zheng, J.Q. Natural transfer of viable microbes in space: 1. From Mars to Earth and Earth to Mars. Icarus 2000, 145, 391-427. [CrossRef] [PubMed]

115. Malin, M.C.; Bell, J.F.; Cantor, B.A.; Caplinger, M.A.; Calvin, W.M.; Clancy, R.T.; Edgett, K.S.; Edwards, L.; Haberle, R.M.; James, P.B.; et al. Context camera investigation on board the Mars Reconnaissance Orbiter. J. Geophys. Res. Planets 2007, 112. [CrossRef]

116. Smith, D.E.; Zuber, M.T.; Solomon, S.C.; Phillips, R.J.; Head, J.W.; Garvin, J.B.; Banerdt, W.B.; Muhleman, D.O.; Pettengill, G.H.; Neumann, G.A.; et al. The global topography of Mars and implications for surface evolution. Science 1999, 284, 1495-1503. [CrossRef]

117. McEwen, A.S.; Eliason, E.M.; Bergstrom, J.W.; Bridges, N.T.; Hansen, C.J.; Delamere, W.A.; Grant, J.A.; Gulick, V.C.; Herkenhoff, K.E.; Keszthelyi, L.; et al. Mars reconnaissance orbiter's high resolution imaging science experiment (HiRISE). J. Geophys. Res. Planets 2007, 112. [CrossRef]

118. Ivanov, B.A. Mars/Moon cratering rate ratio estimates. Space Sci. Rev. 2001, 96, 87-104. [CrossRef] 